\title{
LAS RENTAS SEÑORIALES DEL CONDADO DE ELDA A FINALES DEL ANTIGUO REGIMEN. LOS DIEZMOS
}

Glicerio SANCHEZ RECIO.

Universidad de Alicante

A pesar de las grandes dificultades que existen para el estudio del régimen señorial, en el País Valenciano disponemos de algunas ventajas en buen número de señoríos por la reestructuración que se dio a principios del siglo XVII, después de la expulsión de los moriscos. A. Gil Olcina y E. Císcar Pallarés han tratado de la conformación de los señoríos partiendo de las Cartas de Población, destinadas a la repoblación del v́iejo Reino(1). La de la villa de Elda, presumiblemente aplicada en todo el Condado, establece las relaciones entre la Señoria y los vasallos: jurisdiccionales, económico-contractuales y feudo-señoriales (2). Pero cuando se quiere conocer en profundidad esas relaciones o algún aspecto de las mismas topamos con importantes obstáculos.

En el tema que nos ocupa, esas dificultades se acrecientan porque, a pesar de la minuciosidad de las contabilidades, las anotaciones no se hacen de manera sistemática y la documentación de la que se dispone es muy escasa. La fuente principal del presente trabajo ha sido el Libro del Arrendamiento del Condado de Elda, 1805-1810(3), completada por el Libro Cobratorio de Pechos y Diezmos de Elda. Año de 1809 y por el Contralibro de Elda. Año de $1810^{(4)}$, que tienen la caracteristica común de ser los libros de caja de los arrendatarios; sin embargo, si la información es exhaustiva 
para la villa de Elda, no ocurre lo mismo para la villa de Petrel y el lugar de Salinas. De ahi que hayamos acudido a fuentes fiscales (padrones de haciendas de cada uno de los pueblos) y a otras de carácter notarial.

\section{Las rentas del Condado.}

Documentación fundamental para seguir la evolución de las rentas del Condado, tanto de los capítulos como de las cantidades, son las escrituras de los arrendamientos. A través de las de $1725^{(5)}, 1757^{(6)}$ y 1784 (n) se ve el crecimiento del precio del arrendamiento a lo largo del siglo XVII y el mayor cuidado y precisión en el enunciado de cada una de las rentas y de las obligaciones de los arrendatarios. Según ellas el precio anual del arrendamiento asciende sucesivamente:

$\begin{array}{ccc} & \begin{array}{c}\text { Precio } \\ \text { (libras val.) }\end{array} & \begin{array}{c}\text { Años de } \\ \text { duración }\end{array} \\ 1725 & \text { 3. } & 4 \\ 1757 & 3.900 & 6 \\ 1784 & 10.150 & 6\end{array}$.

Lo que se arrienda, según la primera de las tres, son «los frutos, censos, Regalías, Luismos y demás derechos dominicales de la expressada Villa de Elda y su término en qualesquiera manera tocantes y pertenecientes al Excmo. Sr. Conde...". Y cuando en los capitulos del contrato se vuelve sobre los anteriores términos, se dice en el primero: "... En dicho arrendamiento hayan de entrar y entren todas y qualesquiera rentas que en qualquiera manera pertenezcan y pertenecieren al Señorio, como son los frutos de qualquiera género, granos, censos, erbages y otro qualquier fruto, assi por razón de diezmo, Terciodiezmo y primicia pertenecientes a dicho Excmo. Sr. Conde...». ,Y en el segundo, referido a las regalías del señor, se enumeran "los molinos de aceyte, y arina, hornos, tavernas, mesón, graneros, bodegas y habitaciones, que se han acostumbrado a dar, y arrendar a los demás arrendadores, exceptuando el Palacio de dicha Villa de Elda...".

En cambio, en la segunda, la enumeración es mucho más completa, tanto de las rentas y regalías que se arriendan como de las obligaciones del arrendatario. En ella se lee:

"...los derechos del señorío del Condado de esta misma Villa que le componen Elda, Petrel y Lugar de Salinas, y son las regalias del Tacón de las carnicerías de las tres Poblaciones, el almahazen del aceite del palacio de esta Villa de Elda, solo las casas del Señorío de Petrel y Salinas, la casa mesón, 
graneros y bodega de Elda, con las tinajas, cubas y demás arreos del almahazen y bodega, el huerto y jardín, de los molinos harineros de arriba, de abajo y del pantano de esta Villa de Elda, el de arriba y el de abajo de Petrel, los hornos de cocer pan de Petrel, y el de vidrio de Salinas, los hornos de cocer pan en esta Villa de Elda, que son el de S. Roque, el de S. Francisco, y el de S. Antonio, la tienda de Salinas, y el derecho de percivir al año, con los dos molinos de aceite de la Villa de Petrel, ochenta libras con la tienda, la casa mesón de dicho Lugar de Salinas, y todas las demás regalías pertenecientes al Señorío de dicho Excmo. Señor mi principal en las referidas tres Poblaciones de Elda, Petrel y Salinas, y de los frutos tanto de los diezmos, como de partición que los vasallos y terratenientes de las dichas tres poblaciones devemos pagar al dicho Señor Excmo., y el gasto y disfrute de todas las yervas del término de ellas, $y$ todos aquellos derechos del Señorío en dichas tres poblaciones y sus términos hagora de dicho Excmo. Señor y al presente goza y posee quieta y pacificamente, $y$ los vasalios $y$ terratenientes han pagado y pagan sin la menor contradicción».

En el capítulo cuarto de la escritura del arrendamiento se relacionan algunas de las obligaciones del arrendatario, «pagar las cargas de justicia que sobre sí tiene dicho Condado en los mismos dias que se devengasen»: dos mil libras a la Tablas de los Oidores de Valencia, el subsidio y el excusado a la ciudad de Orihuela, cien libras por la composición de diezmos a dicha ciudad, lo que importare el cuatro por ciento, lo estipulado a los curas y a las fábricas de las iglesias parroquiales de Elda, Petrel y Salinas, las subvenciones al convento $y$ al hospital de la villa de Elda, los salarios del alguacil del Condado $y$ otros si hubiere, y las obras y reparaciones que se hicieren. Estos pagos los realizará en nombre del señor, pero caerán sobre el arrendatario los daños $y$ perjuicios causados en caso de no efectuarlos en los plazos señalados (ver el protocolo citado en la nota 6).

Los capítulos y condiciones de la tercera no nos son conocidos; sin embargo, en la escritura de fianza del arrendamiento del Condado de Elda, del 26 de noviembre de 1784, se dice: «...Arrendó y por título de arrendamiento dio y concedió al compareciente (J. Pérez y Bernabé) los derechos dominicales y decimales del Señorío del Condado de Elda que se compone de la Villa de este nombre, Petrel y Lugar de Salinas con todas las regalías, emolumentos y derechos que a Su Excia. le pertenecen en dichos tres lugares por tiempo de seis años precisos... ${ }^{(8)}$. Y en el Libro del Arrendamiento del Condado aparece especificada cada una de las rentas y de las regalías. 
Otra vía que nos acerca además al valor de las rentas del Condado son los padrones de haciendas, según los cuales el Conde tenía:

\begin{tabular}{|c|c|c|c|}
\hline \multirow[b]{2}{*}{ Elda(9) } & $\begin{array}{l}\text { Propiedad } \\
\text { en reales }\end{array}$ & Renta en reales & R. Libras \\
\hline & - & - & $5.371-3-$ \\
\hline Petrel(10) & 25 & & $36-12-$ \\
\hline alinas(11) & 13.600 & & $36-7-$ \\
\hline \multicolumn{4}{|c|}{$\begin{array}{l}\text { El total de la renta estimada, como puede verse, a pesar de que faltan } \\
\text { os diezmos y los pechos de Salinas, queda muy por debajo del precio del } \\
\text { arrendamiento de } 1784 \text {. }\end{array}$} \\
\hline \multicolumn{4}{|c|}{$\begin{array}{l}\text { Sin embargo, a través de los libros de caja de los arrendatarios la re- } \\
\text { alidad es distinta. En éstos la renta aparece distribuida en tres grandes } \\
\text { apartados: los pechos y el luismo, en función del dominio directo, las } \\
\text { regalías y monopolios señoriales, y los diezmos, y otros de menor impor- } \\
\text { tancia, como la renta del huerto del Conde en Elda, aunque son difíciles de } \\
\text { distinguir unos de otros por el método seguido en las anotaciones(12). }\end{array}$} \\
\hline
\end{tabular}

\subsection{Los pechos.}

La tierra y las casas del Condado, después de la expulsión de los moriscos, se habian dado a censo enfitéutico a perpetuidad, lo que suponía el pago de un pecho o canon por los vasallos, tanto de las repartidas a principios del siglo XVII(13), como de las concedidas y roturadas en el siglo XVIII(14).

Los pechos pagados por la villa de Elda nos son bien conocidos por las Giradoras desde el siglo XVII al XIX y por la serie de cuentas de los vasallos con el colector del Conde a lo largo del siglo XVII(15). Según los libros de caja pagaba:

Pechos de la Villa de Elda de $1805 \ldots .$.

$$
\begin{array}{r}
1.158-18-2 \text { (Lib. }- \text { S. }-D .) \\
12-7-2 \text { (Lib.-S.-D.) }
\end{array}
$$

Señoría directa de Elda de 1805 .......

Total ...........

\begin{tabular}{|c|c|c|c|}
\hline N. ${ }^{\circ}$ Pechers. & Categoría & Lib.-Suel.-Din. & $\%$ del tota \\
\hline 588 & Vecinos & $1.278--11$ & 74,10 \\
\hline 43 & Terratenientes de fuera ..... & $100-11-4$ & 5,80 \\
\hline 69 & Terratenientes de Petrel. ..... & $242-2-5$ & 14,00 \\
\hline \multirow[t]{5}{*}{80} & Señoría directa .......... & $31-4-$ & 1,90 \\
\hline & Iglesia ........... & $70-1-1$ & 4,05 \\
\hline & Villa de Elda $\ldots . \ldots \ldots \ldots$ & $15-2$ & 0,04 \\
\hline & Conde de Elda. & $2-\quad-9$ & 0,11 \\
\hline & Total . & $1.724-15-8$ & 100,00 \\
\hline
\end{tabular}

En 1809, de manera más precisa, Elda pagaba(17): 
Las diferencias entre una y otra fuente son notables, evidentemente más completa y fiable la segunda. Los pechos de los 588 vecinos están distribuidos por calles; de ahí que, como puede verse en el cuadro l, se dé un reparto muy desigual entre unaś y otras calles: las once primeras calles, cuyos pechos per capita son superiores a la media, abarcan el $35,54 \%$ de los vecinos y el $65,33 \%$ de los pechos pagados; las ocho siguientes (de la 12 a la $19)$, con pechos inferiores a la media pero superiores a una libra, tienen el 27,04 de los vecinos y el $25,18 \%$ de los pechos pagados; $y$, finalmente, las once últimas (de la 20 a la 30 ), con el $37,42 \%$ de los vecinos, tienen sólo el $9,49 \%$. En el plano adjunto se hallan localizadas las calles con pechos más altos en el centro y en la periferia del E. y del NE. de la villa.

No contamos con información tan abundante sobre los pechos que pagaba la villa de Petrel. Esta tenia una población, a finales del siglo XVIII, de 2.636 habitantes, según el censo de Floridablanca(18) y de 500 vecinos, según Cavanilles ${ }^{(19)}$, de los que, según el primero, 114 eran labradores, 213 jornaleros y 29 artesanos, y todos ellos debían ser vasallos del Conde. Ante estos datos consideramos que las 147-15- 6 (libras-sueldos-dineros) que aparecen en el Libro del Arrendamiento son una cantidad excesivamente baja, tratándose, quizá, de una entrega parcial; de ahí que pensemos como cantidad más fiable los 12.595 reales que constan en el Libro Padrón de Haciendas de la villa de Petrel de 1818 como "pechos... y demás derechos dominicales», exceptuados los diezmos y demás regalías que se enumeran en el propio Libro Padrón(20). Estos libros eran elaborados por mandato del Ayuntamiento y la fuente de documentación principal para esta partida eran los libros de Giradora controlados también por el propio Ayuntamiento(21). El resto de los derechos dominicales eran de escasa entidad, los luismos y las penas de cámara. De ahí que los pechos de la villa se aproximaran a las 800 libras.

Mayor problema existe en lo relativo a los pechos del lugar de Salinas. Su población, según el censo de Floridablanca, era de 521 habitantes, y 80 vecinos, según Cavanilles, y 21 labradores y 62 jornaleros, según el primero de éstos(22). En la Giradora de la villa de Elda de 1716, en vigor hasta 1745 , se recogen los pechos que los vecinos y terratenientes de Salinas pagaban a la Señoría. Eran catorce entre unos y otros y respondian con 35-2-1 (libras-sueldos y dineros)(23). No contamos con información posterior acerca de los pechos pagados por Salinas, aunque la situación no varió grandemente a lo largo de la segunda mitad del siglo XVIII, según se desprende de comparar los datos del informe municipal de 1747 con los aportados por Cavanilles.

Así pues, de todo lo anterior puede deducirse que los pechos del Condado de Elda se aproximaban a las 2.600 libras valencianas. 


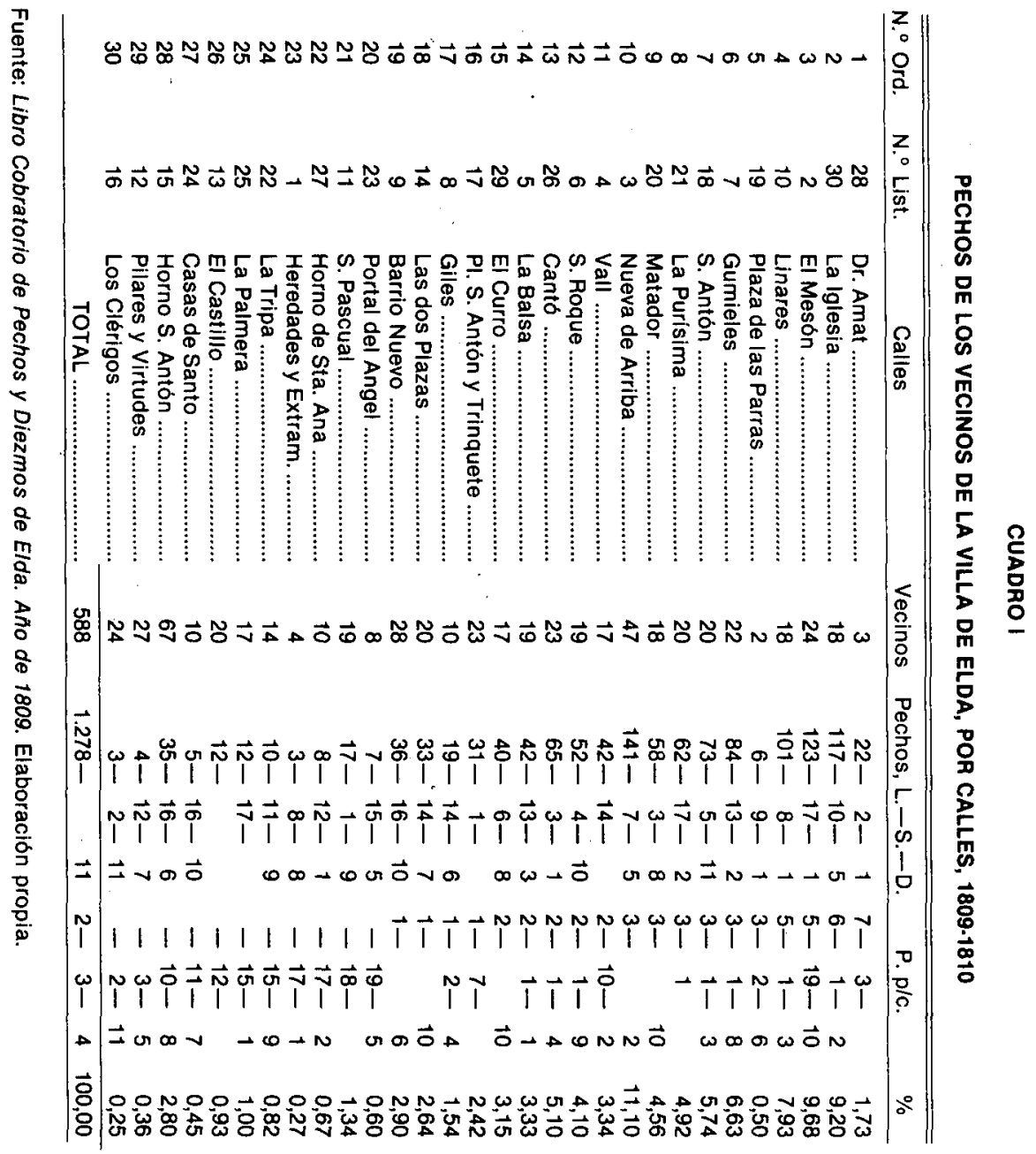




\section{PLANO DE LA VILLA DE ELDA}

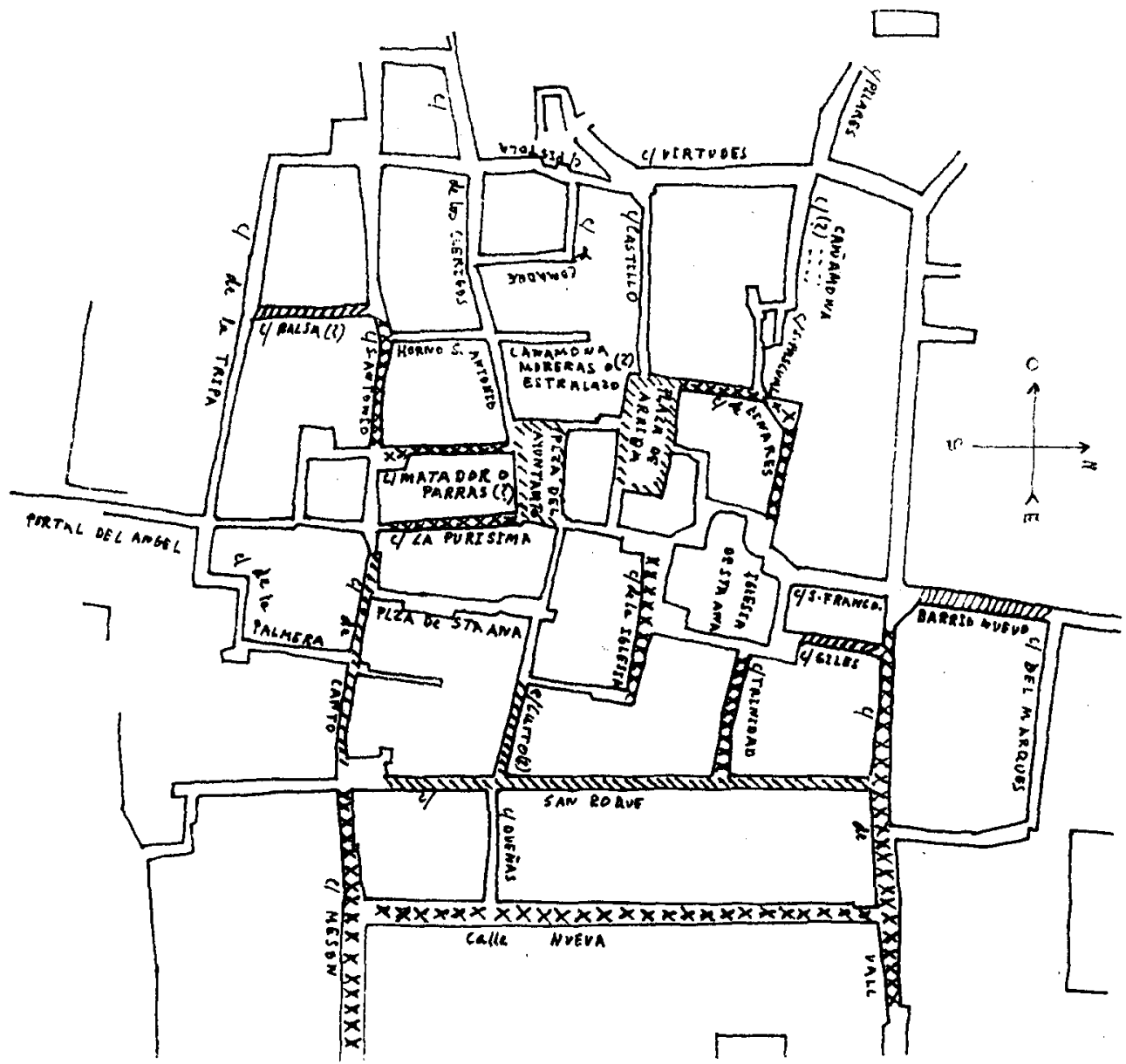

XXX Calles con Pechos p/c. superiores a la media. Suponen el 65,33\% del total.

IIII Calles con Pechos p/c. inferiores a la media y superiores a una libra. Suponen el $25,18 \%$ del total. 


\subsection{Las regalias y los monopolios señoriales.}

La renta señorial del Condado de Elda por este concepto se situaba por encima de las 4.000 libras, aunque precisar la cantidad supone grandes dificultades.

El origen de estas rentas entronca con la esencia misma del señorío. Los señores las cobraban en virtud de la potestad que ejercían sobre el territorio y la población de su señorio, por la que se convertían en soberanos intermedios o "reyes chiquitos» (24). De ahí que las Cortes de Cádiz, al abolir los señorios jurisdiccionales por el decreto del 6 de agosto de 1811, dedicaran el artículo séptimo del mismo a esta cuestión, en el que se decia: "Quedan abolidos los privilegios Ilamados exclusivos, privativos y prohibitivos que tengan el mismo origen de señorío...)(25). A través de esos poderes los titulares del señorío, además del cobro de los censos o pechos por la explotación de la tierra y la posesión de las casas, controlaban las actividades de los sectores secundario y terciario, fundamentales en una economía de subsistencia, como las destinadas a la elaboración y comercialización de los productos agrarios.

Estas regalias eran de gran interés económico, porque con sus rentas los señores compensaban en parte el estancamiento de los pechos, y fueron objeto de un gran cuidado y vigilancia. Así se enumeran en la Carta de Población de Elda, cuyo capítulo 22 está redactado en estos términos:

«Ittem es tractat y concertat que la venderia del pa, vi, y altres coses per menut ha de respectar a la persona o persones que lo dit Señor Conte señalara en axi que la flaqueria, taverna, hostal, forns, molins, almasares y quasevol altres venderies per menut excepto les tendes respecten al dit Señor Conte de haverlos perpetuament com sempre les ha tengudes y li respecten ab antico y resta facultat a dits pobladors per a entrar vi de fora al terme per a son beure tan solament".

Se recogen también en el contrato de arrendamiento de 1757, citado más arriba, y en el caso concreto de las regalías de Salinas se detallan y àctualizan en la Concordia firmada entre el Conde y el Ayuntamiento de Salinas, el 27 de noviembre de 1760, en la que se dice:

"Que hallándose dicho Sr. Excmo. en la quieta y pacífica posesión de Inmemorial del Dominio, Señorio y Vasallaje, Jurisdicción Civil y Criminal, Mero y Mixto Imperio de dicho Lugar y su término, ... con el goce igualmente de varios derechos y regalias, como son: de tener tienda, panaderia y taberna, casa mesón, horno de vidrio, derecho de borra, con el uso de las yervas del término de este Lugar ... Todo en fuerza de legítimos títulos, como dueño y Señor del Condado de Elda en el que está comprendido dicho Lugarn (Apéndice, Documento I)(26). 


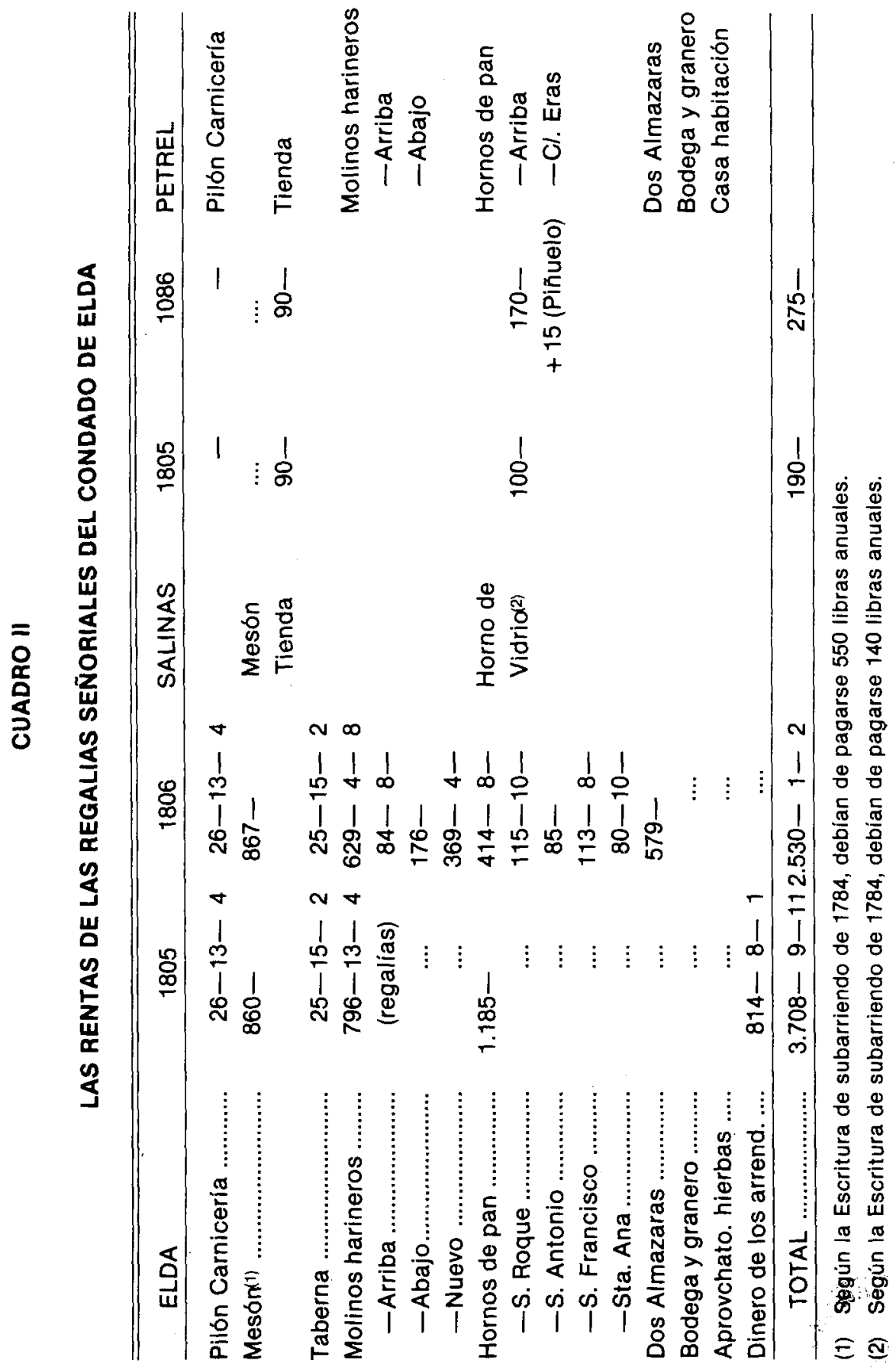


En el cuadro Il se han recogido las regalias señoriales de cada uno de los pueblos y las rentas correspondientes a 1805 y 1806 de Elda y Salinas, según el Libro del Arrendamiento, ya que las de Petrel aparecen todas juntas, sin distinción, a nombre de uel colector de Petrel». Aparte de la importancia de estas rentas, únicamente queremos hacer notar la diferencia que existe entre los ingresos de uno y otro año en los hornos de pan de Elda, cuya explicación, a pesar del descenso de los precios, nos está vedada por la documentación.

\section{Los diezmos.}

Constituyen éstos con mucho la renta principal del Condado. Los diezmos, a pesar de su origen, no fueron una renta exclusiva de la Iglesia. Gil Olcina trata de la reglamentación de los del Reino de Valencia realizada por Jaime I en el título 24 del fuero primero(27). Quedaron divididos en tres partes, siendo sus destinatarios: el clero secular, la fábrica de las iglesias y la hacienda real, y se fijaron los productos que diezmaban y la proporción en que lo hacian; sin embargo, con el paso del tiempo variarán tanto los partícipes de esta renta, como las proporciones de pago de cada uno de los productos. La innovación principal consistió en la apropiación por los señores, siguiendo distintos medios, de la parte correspondiente a la hacienda real, llegando en algunos casos, como en el que nos ocupa, a apoderarse de la totalidad de los diezmos. Por su parte, A. Mestre Sanchis se ha hecho cargo de la gran variedad que alcanza el pago del diezmo de cada uno de los productos en la diócesis de Valencia(28).

\subsection{El Condado, "único llevador de los diezmos".}

El Condado de Elda era, por tanto, una de las excepciones en las que los señores eran «los únicos llevadores de sus diezmos». Así lo exponía el 4 de enero de 1774 don José Tormo, Obispo de Orihuela, en un informe dirigido al Real Consejo, en respuesta de una orden del 30 de octubre de 1773, en la que se pedía el número de "fanegas de trigo y cebada", producto de los diezmos de cada una de las diócesis, en los 18 años comprendidos entre 1756 y 1773 :

"...Resulta lo que consta por el plan adjunto que dirijo, no incluyéndose en él, Elda, Novelda, Aspe, Petrel, Salinas y Monóvar, por ser únicos llevadores de sus diezmos los señores temporales, y estar arrendados juntamente con los demás derechos dominicales, y no haber por ello podido liquidarse.... (29).

Esta situación arrancaba de varios siglos atrás, anterior incluso a la creación del propio Condado. En agosto de 1494, en la villa de Aspe, se 
firmaba una Concordia entre el Conde de Cocentaina, señor de los lugares de la villa de Elda, "a saber: Elda, Aspe, Petrel y Salinas", y el Cardenal de Cartagena, a cuya diócesis pertenecian dichos Lugares, cuyo objeto era solucionar "la diferencia que el dicho Espectable Señor Conde tiene con su Señoría Reverendísima y su Iglesia de Cartagena acerca de los diezmos de los Lugares...". Los principales capítulos establecidos eran:

a) Dadas las dificultades que existían en dichos lugares para el cobro de los diezmos, por ser «poblados de moros", el Conde habría de dar "en cada un año perpetuamente para siempre jamás a los Señores Obispo, Deán, y Cabildo de la dicha Iglesia de Cartagena doscientas libras de moneda reales de Valencia por la parte que a ellos cabe de los diezmos de los dichos Lugares...".

b) Aparte de lo anterior, el Conde ha de mantener un clérigo y un Rector en la villa de Aspe y otro en la de Elda y pagar a la fábrica de dichas iglesias lo "justo" para los ornamentos y sus necesidades.

c) Se especificaban los frutos de los que se había de pagar diezmo y éste consistiría en la octava parte. (Apéndice, Documento II)(30).

Esto mismo se recoge en la Carta de Población. En el capítulo $15 \mathrm{se}$ dice que al Conde le pertenecen los diezmos y primicias de todos los frutos de las villas de Elda y de Petrel «a just titol y concessio de Sa Santetat", y que se ha de pagar la octava parte "ço es, set parts per a dits nous pobladors y una per a el Señor Conde y sos successors"; sin embargo, el diezmo de los ganados era la décima parte (capt. 21). En las correcciones de 1612 se establecia que en el diezmo de las olivas se pagara la séptima parte, a cambio de la desaparición del censo de este producto(31).

El diezmo, debido a su origen, tenía una mayor extensión que la renta señorial; de ahí la obligación de pagarlo por todos los frutos y por todos los vasallos del Conde, tanto de los de las tierras sometidas a censo enfitéutico como de las alodiales, tierras de natura/(32).

En la segunda mitad del siglo XVIII surgió de nuevo el conflicto entre el Conde y la Iglesia. La población del Condado había crecido y con ésta las necesidades pastorales, y el valor de los diezmos era notablemnte superior por el crecimiento de la producción y la subida de los precios; de ahí que el Obispo de Orihuela, don José Tormo, gran valedor de los derechos de la Iglesia, pidiera la actualización de la vieja Concordia de 1494(33). A la vista de los informes presentados por los comisionados del Conde y del Obispo, éstos se pusieron de acuerdo sobre "las obras que se habian de hacer, aumento de congruas a los ministros y sirvientes de dichas Iglesias, y ornamentos para el culto divinon, estableciéndose los capitulos siguientes: 
1) Villa de E/da

a) La obra principal de la Iglesia de Elda se realizaría durante los diez años próximos "por ser muy costosa y no haber urgente necesidad en el día".

b) Al cura no se le aumenta la congrua. Dispone de 113 libras y 10 sueldos "mediante que con ella y otros emolumentos compone cerca de quinientas libras anuas".

c) Al vicario se le aumentan 150 libras a las 50 que ya tenia uen calidad de teniente de curan.

d) Creación de un segundo teniente, cuyas funciones serán:

«ayudar al Párroco, diciendo la Misa en los dias festivos en la Hermita que su IIIma. elija en el campo con proporción a las quinterías que habitan vecinos varios, donde asímismo ha de cuidar de la administración de Sacramentos en los casos muy urgentes, y no más, mediante que aunque los feligreses sean pobres se pueden fácilmente conducir al Hospital que su Excia. mantiene a su expensas en dicha villa, donde serán mejor asistidos que en el campo, con el cuidadoso zelo de veinte y quatro religiosos franciscos, que igualmente mantiene su Excia. con la obligación de ayudar al Párroco, asistencia de enfermos, y demás conducente al consuelo espiritual de los vecinos, en cuya consideración queda por convenio suspendida la dotación de este segundo teniente hasta que su IIIma. informe a su Excia. con conocimiento de la necesidad, situación de la Hermita, y cantidad anual, y que prointerin cuide de esta obligación, como está ejecutando uno de los religiosos franciscos, que su Excia. mantiene".

e) Al sacristán primero se le añaden 30 a las 20 libras que ya tenia, pero se le quita el usufructo de un bancal de tierra que antes gozaba.

f) Al segundo sacristán se le cede el anterior bancal y se le dan las 20 libras del salario.

g) Se crean dos plazas de monaguillos con cinco libras de salario anual para cada uno.

h) A la fábrica se le otorgan 200 libras al año para atender «a los reparos y gastos menores de la Parroquia, mejor aseo y servicio de culto divino".

i) El dotar a la Iglesia de los ornamentos necesarios «queda al arbitrio y cuidado de su Excelencian.

j) Queda al cuidado de su Excia. dotar a la Iglesia de organista, que a la vez ha de ser "maestro de primeras letras", y ponerse de acuerdo con el Ayuntamiento de la villa para ajustar el salario. 
2) Villa de Petrel

a) Se conceden a la fábrica de la Iglesia 100 libras para reparos menores.

b) Al cura no se le aumenta cantidad alguna a las 100 libras que recibía.

c) Al sacristán se le añaden 10 a las 15 libras que anteriormente tenía.

d) Se crea un segundo sacristán con el suelo de 10 libras anuales.

e) Sobre el organista se establece lo mismo que lo acordado para la villa de Elda.

3) Lugar de Salinas

"La Parroquial del Lugar de Salinas no necesita en el día reparo alguno, mediante averse fabricado de nuevo en el año de mil setecientos cincuenta y cinco a expensas de su Excia. por la inundación que padeció aquel pueblo y su Iglesia, aviendo sido preciso mudar uno y otro de sition.

Sin embargo, se establece:

a) Conceder a la fábrica 60 libras anuales upara gastos menores".

b) Añadir al cura 100 a las 100 libras que recibía, con la obligación de pagar de su cuenta al sacristán.

c) Crear en el futuro plaza de teniente o capellán que ayude al cura.

Entre las condiciones acordadas para la puesta en práctica de los anteriores capítulos se establece "que en atención a lo urgente y privilegiado de estas dotaciones y demás estipulado en la Concordia, se deberán pagar en los mismos pueblos por los procuradores, administradores o arrendadores del Conde, con preferencia a todas las demás cargas del Estado, a plazos determinados, y regulando los frutos al precio corriente que tuvieren en aquel tiempo".

Así pues, según la Concordia, el Conde habia de pagar, a partir de 1769, a las parroquias del Condado:

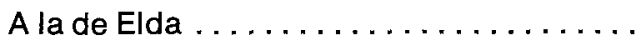
593-10 Libras-Sueldos

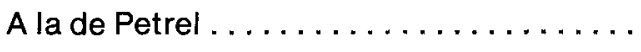

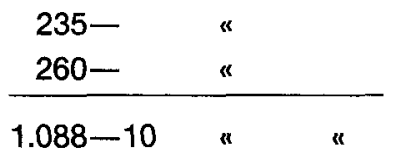

A la de Salinas 
Cantidad a la que hay que añadir los gastos de la obra de la Iglesia de Elda, la creación de los nuevos tenientes de cura de Elda y Salinas y el salario de los organistas de Elda y Petrel.

\subsection{Los diezmos de la Villa de Elda entre 1805 y 1810.}

\subsubsection{Producto y valor neto de los diezmos de Elda.}

A través de los libros de caja de los arrendatarios, disponemos de una completa información para estos años. En los tres libros consta el producto de los diezmos, ya se pague en especie, ya en dinero, pero, de manera precisa, especificando cada uno de los frutos, sólo en los de la villa de Elda; los de Petrel y Salinas se anotan como "entregas del colector", y, sobre todo los de Petrel, mezclados con el resto de las rentas. En el Libro del Arrendamiento se detalla el producto de cada uno de los diezmos, lo que corresponde a los partícipes y los precios con los que se da salida a dichos productos.

A través de los cuadros III y IV puede verse la gran variedad y amplitud de frutos por los que se paga el diezmo, cuales eran los cultivos dominantes y la fluctuación de las cosechas, a pesar de la corta serie aquí utilizada. Los productos de mayor peso eran el trigo, la cebada, el panizo, el aceite y el vino, entre los que se pagaban en especie, y las hortalizas en general y la uva, entre los que se pagaban en dinero. No podemos precisar acerca de la barrilla porque sólo en 1809 presenta una cantidad importante. En cuanto a la fluctuación de las principales cosechas, la del trigo se queda por debajo de la media en 1807, 1808 y 1809; es mayor la irregularidad de la cebada; $y$ el panizo tuvo una caida importante en 1809; sin embargo, fueron mejores las cosechas de 1806 y 1807, esta última, en contraposición a la del trigo y la cebada. Respecto al aceite, nos topamos con la particularidad de ser el olivo un cultivo vecero, $y$, por tanto, con la alternancia de la producción: 1805-1807-1809, y la de 1808-1810, a excepción de la de 1806 , en que se reduce notablemente la producción, con el agravante de que ese año los precios son más bajos (cuadro V), quedando abierto un serio interrogante. Finalmente, hallamos también una perfecta correlación entre el vino y el aguardiente. La recolección del primero sube en 1809 y 1810 , cuando no hay diezmo del segundo; a pesar de esto, los diezmos de 1807 y 1808 fueron inferiores, y el precio del vino en este último año conoció una fuerte subida, aunque sólo fue el principio que se continuaria durante los dos años siguientes. También aquí queda abierto el interrogante sobre el diezmo de 1805, notablemente más bajo que el de los años siguientes.

En el cuadro $\mathrm{VI}$ se recoge el valor neto del producto decimal en especie, es decir, lo que queda en manos de los arrendatarios, una vez deducido lo correspondiente a los partícipes (cuadros VII y VIII). Sin embargo, los 


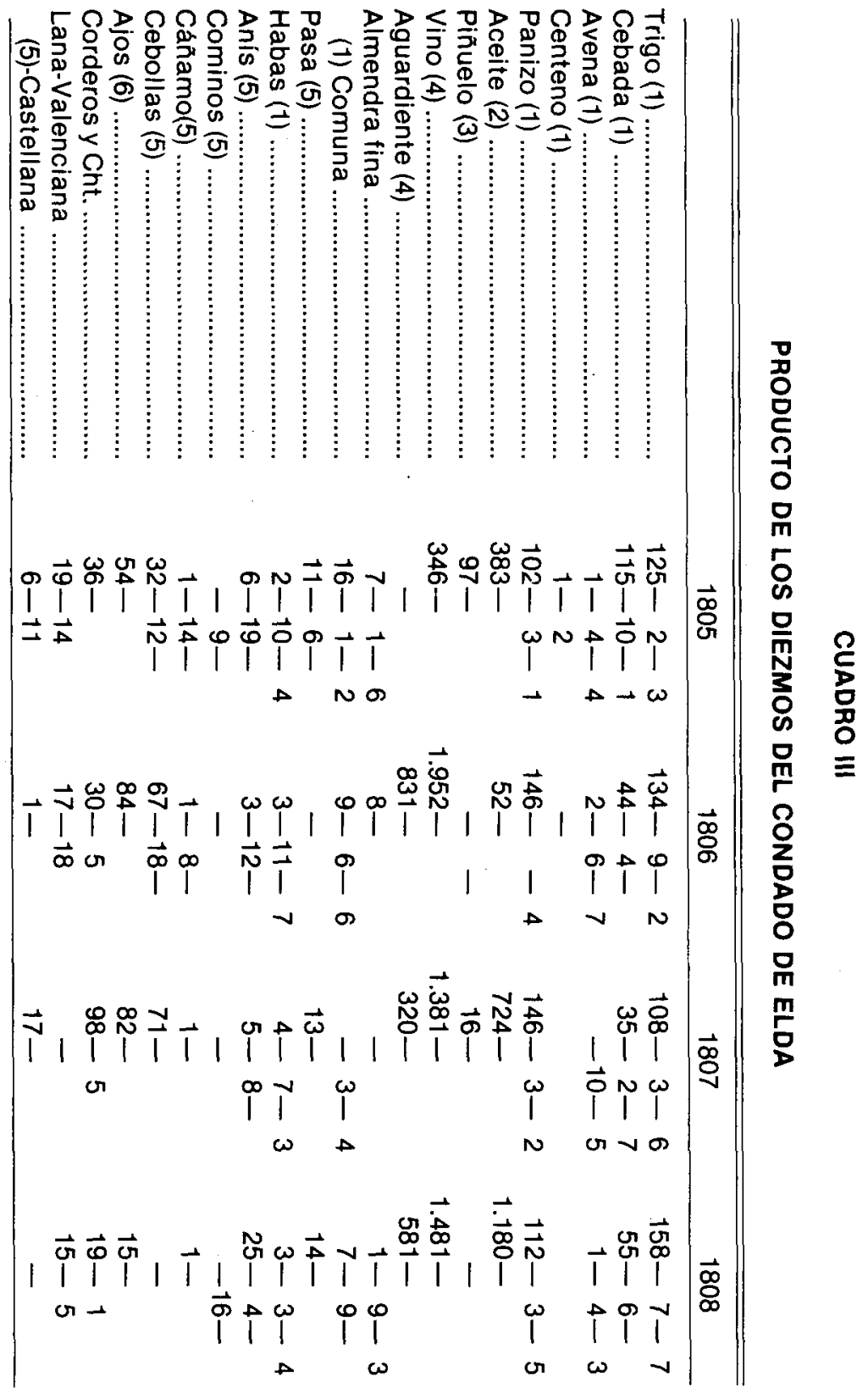




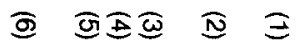

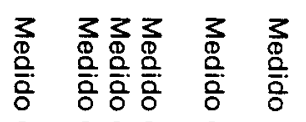

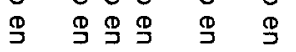

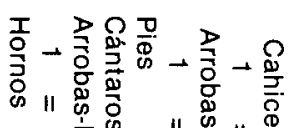

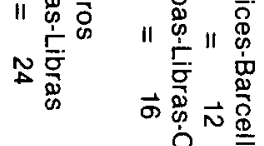
॥

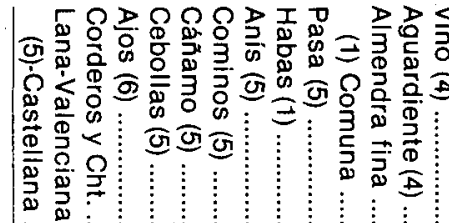

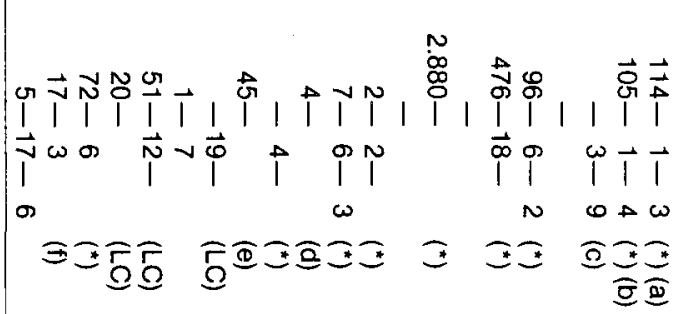

1 T)

$$
=\cos ^{\omega}
$$

w \&

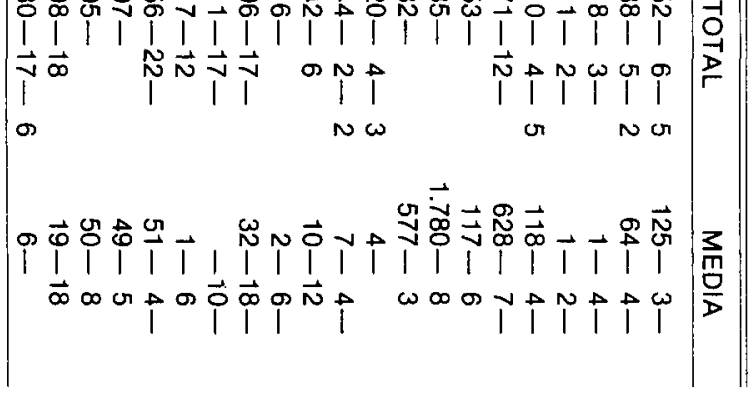


(*) Coincide El Libro del Arrendamiento con El Libro Cobratorio...

(**) Coincide El Libro del Arrendamiento con El Contralibro de 1810.

(a) En El Libro Cobrt., se dice "más 22 Barcellas y 3 Medios".

(b) De ellas correspondieron a Petrel 4 Cah. y 4 Barc. (L. Arrend.).

(c) 9 Barc. 3 Med., según el L. Cobratorio.

(d) 5 Arrobas, según el L. Cobratorio.

(e) 93 Libras 7, según el L. Cobratorio.

(f) 40 Libras (capac.) más 13 Libras y 1 Sueldo (moned.) (L.C.)

(g) 461 Libras, según El Contralibro de 1810.

(h) Incluido el procedente de Salinas (Libro del Arrend.).

(i) El dato procede del Libro Cobrt. En L. Arrdto. se dan 6 Arrb.

(LC) Libro Cobratorio, única fuente utilizada.

\section{CUADRO IV}

DIEZMOS PAGADOS EN DINERO EN ELDA (Lib.-Sel.-Din.)

\begin{tabular}{lrrr}
\hline & $1805(1)$ & $1809(2)$ & $1810(3)$ \\
\cline { 2 - 4 } & & $34-3-$ & $87-4-$ \\
Fruta (4) ............. & & $80-3-$ & $84-18-$ \\
Alfalfa .............. & & $7-9-$ & $7-18-$ \\
Nabos .............. & & $5-18-$ & - \\
Cebollas t......... & & $7-18-$ & $2-$ \\
Chirivías ............ & & $1-15-$ & - \\
Forraje ............. & & $107-14-(5)$ & $92-11-$ \\
Hortalizas ........... & $211-3-8$ & $462-12-$ & $471-$ \\
Uvas .................. & $175-4-4$ & $49-12-$ & $40-4-$ \\
Cardos .............. & $31-8-$ & $134-18-$ & - \\
Barrilla ............... & $47-17-$ & $792-2-$ & $785-15-$ \\
\hline
\end{tabular}

(1) Fuente: Libro del Arrendamiento del Condado.

(2) Fuente: Libro Cobratorio de Elda, Año 1809.

(3) Fuente: Contralibro de Elda, Año 1810.

(4) Incluido el diezmo de Petrel.

(5) Incluido el diezmo de los terratenientes.

(6) Más 28 cargas no valoradas. 


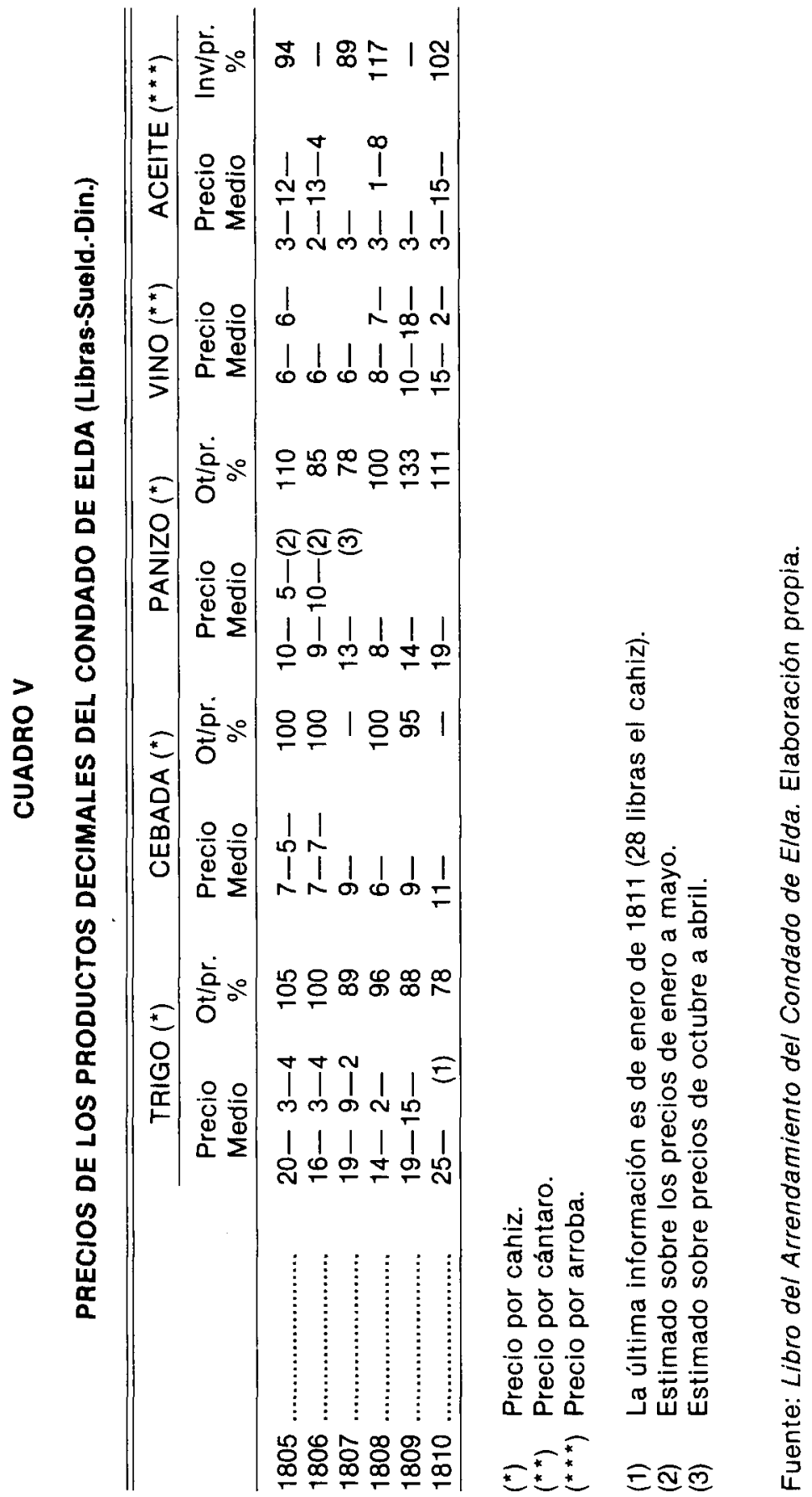




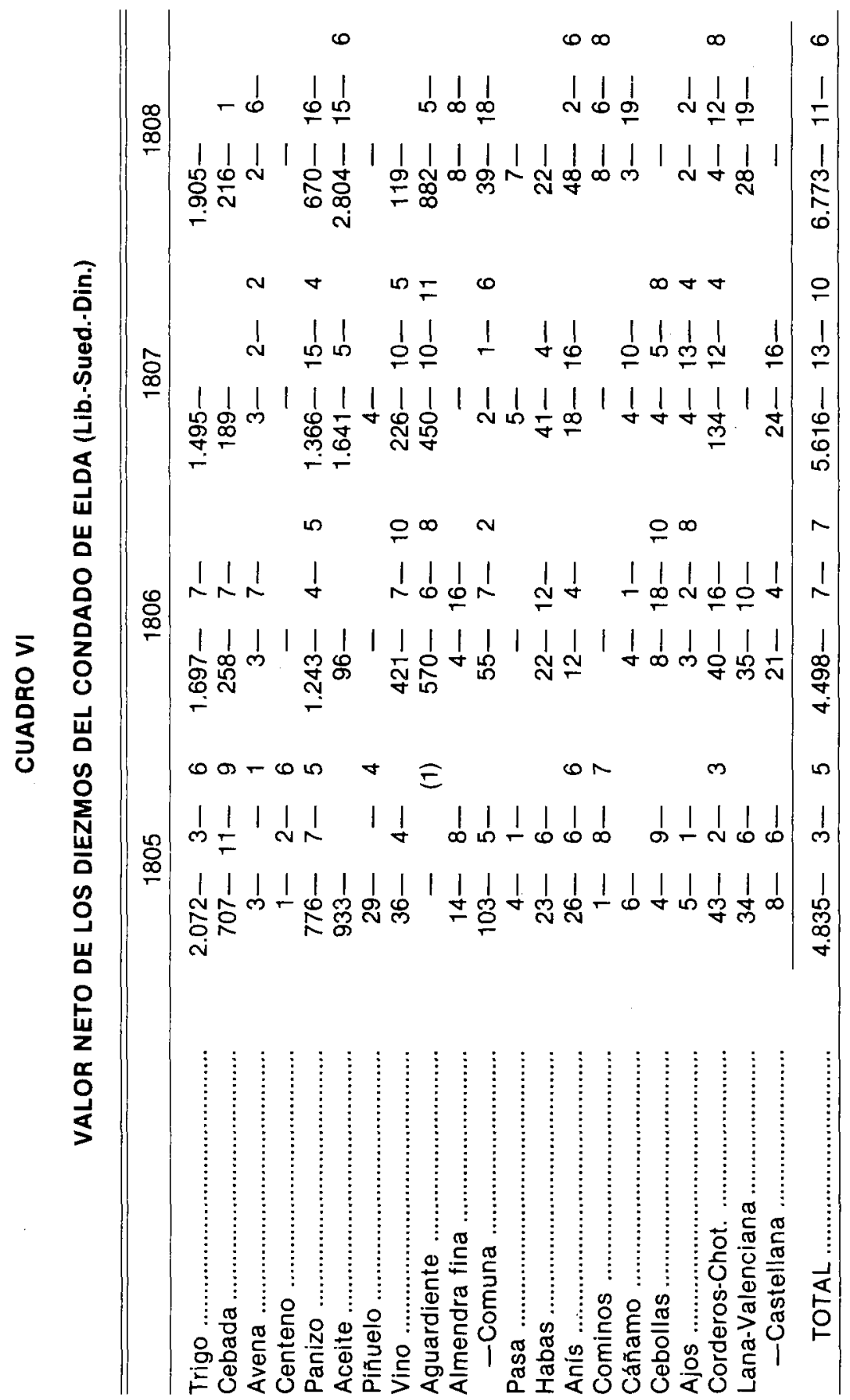




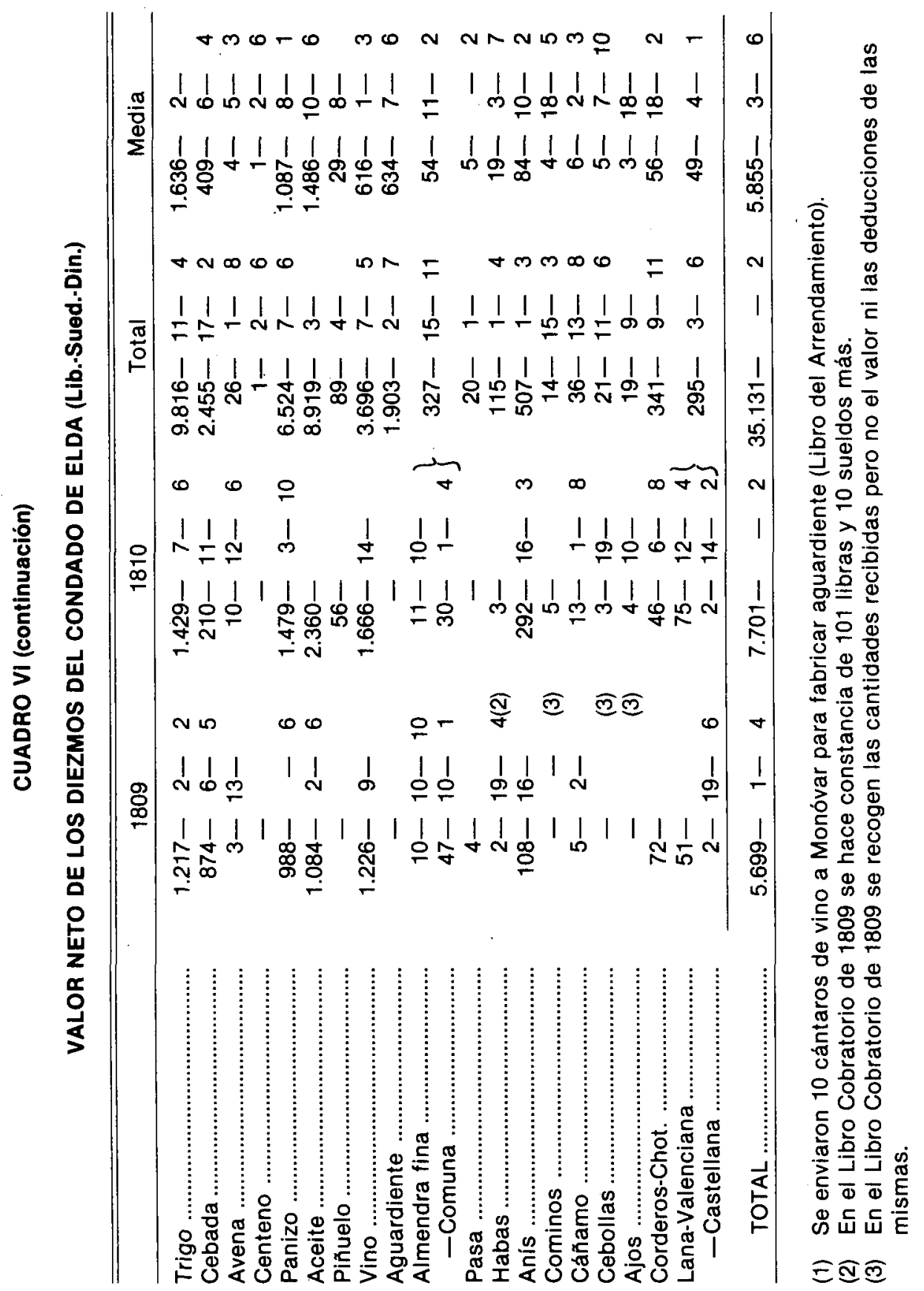


datos de ese cuadro hay que relacionarlos no sólo con los que aparecen en el lil, sino también con los del VII y el VIII y con los precios de los principales productos decimales (cuadro $V$ ). A través de él se observa que la media anual se sitúa en una cantidad próxima a las seis mil libras, quedándose muy por debajo los dos primeros años: en 1805, a pesar de lo elevado del precio del trigo, por la baja recolección del vino, y en 1806, caen los precios del trigo, pero no existen prácticamente entradas por el aceite. Las entradas de 1807 se aproximan a la media, se recuperan los precios del trigo y suben los del maíz, con lo que puede compensarse la mayor salida de los partícipes. En 1808 se da una gran subida, a pesar de la caida de los precios del trigo, de la cebada y del panizo, pero subió considerablemente el ingreso por el aceite. En 1809, los ingresos se aproximan a la media, y en 1810 la superan ampliamente, pero aqui, aparte de otras consideraciones, hay que tener en cuenta la intensa subida de los precios.

Los precios medios de los productos decimales han sido calculados mediante los precios de septiembre-octubre, diciembre-enero y marzoabril, y los hemos acompañado con la relación del precio del otoño y de la primavera siguiente para ver la tendencia anual de los mismos. Según esto, se da una caída de los precios del trigo, del panizo y del aceite en 1806, anunciada por la tendencia otoño-primavera para los dos primeros; se recuperan en 1807 los del trigo y del aceite y suben los de la cebada y del panizo, pero sólo este último fue anunciado por la tendencia; en 1808 se da una profunda caída en los del trigo, la cebada y el panizo, y sólo sube el del vino, que se había mantenido estable en los años anteriores; dándose, finalmente, importantes subidas en 1809 y 1810, a excepción del aceite que mantuvo estables sus precios, aunque en el panizo la relación de otoñoprimavera se mostrara favorable a la baja.

\subsubsection{El producto decimal de los partícipes.}

Es éste un elemento de gran valor, porque nos permite conocer la distribución del producto decimal en dos señoríos en los que el señor era el uúnico llevador de los diezmos". Pero, además, a través del Libro del Arrendamiento, podemos conocer de cerca alguno de los procedimientos de la contabilidad del Antiguo Régimen. Así resulta que los partícipes, y concretamente el Real Noveno y el Cuatro por Ciento (34) solo se deducian de los productos en especie y, más aún, sólo de los recolectados en Elda, porque los de Petrel y Salinas, como ya he dicho, constan como entregas del perceptor respectivo, e, incluso, las partes pertenecientes a los curas de Petrel y Salinas se descontaban de los ingresos de Elda; y tampoco aparece deducción alguna en las cantidades correspondientes a los diezmos pagados en dinero. El principal beneficiario de esta operación era el señor, a costa del cual se realizaban los anteriores pagos. 

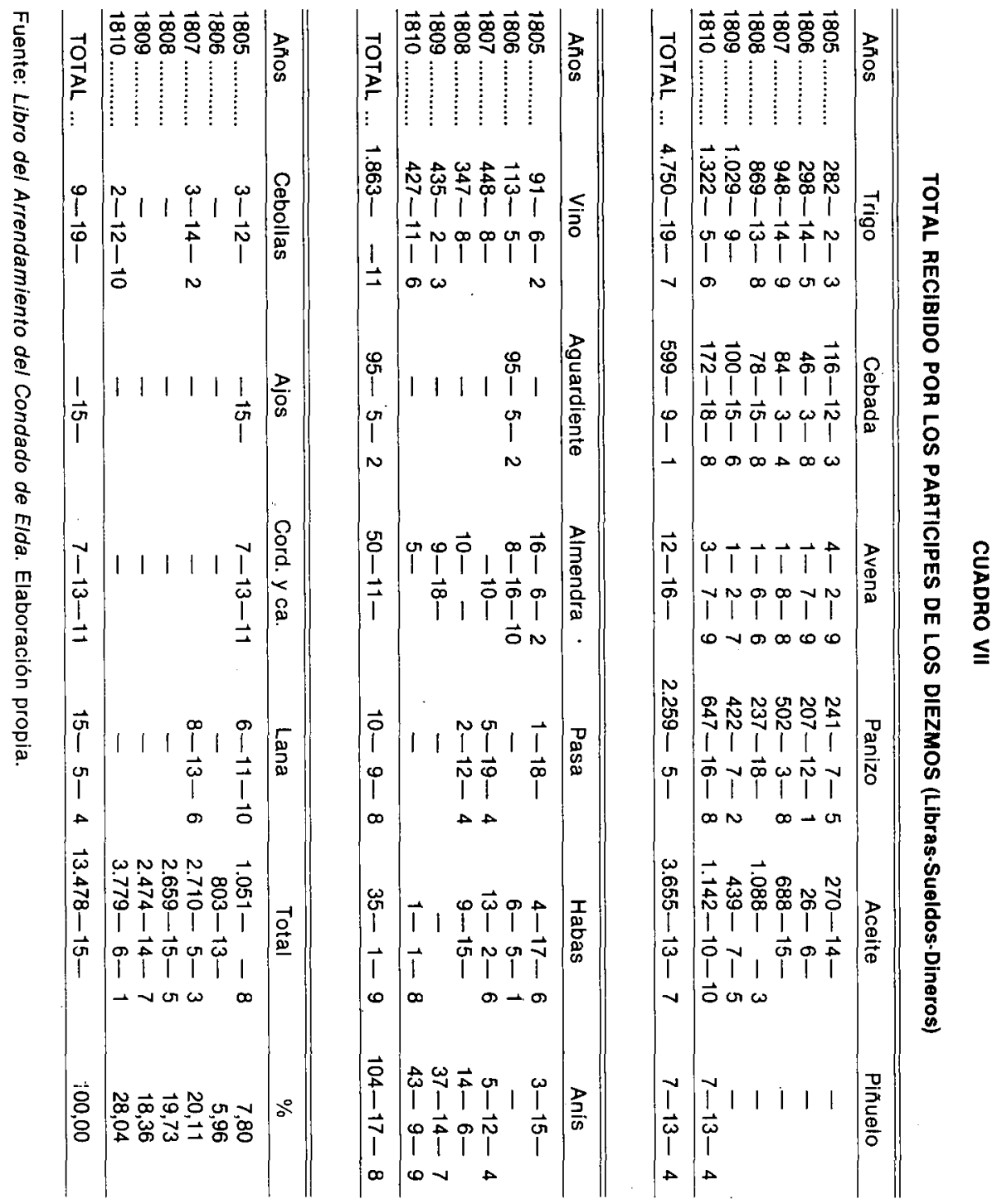


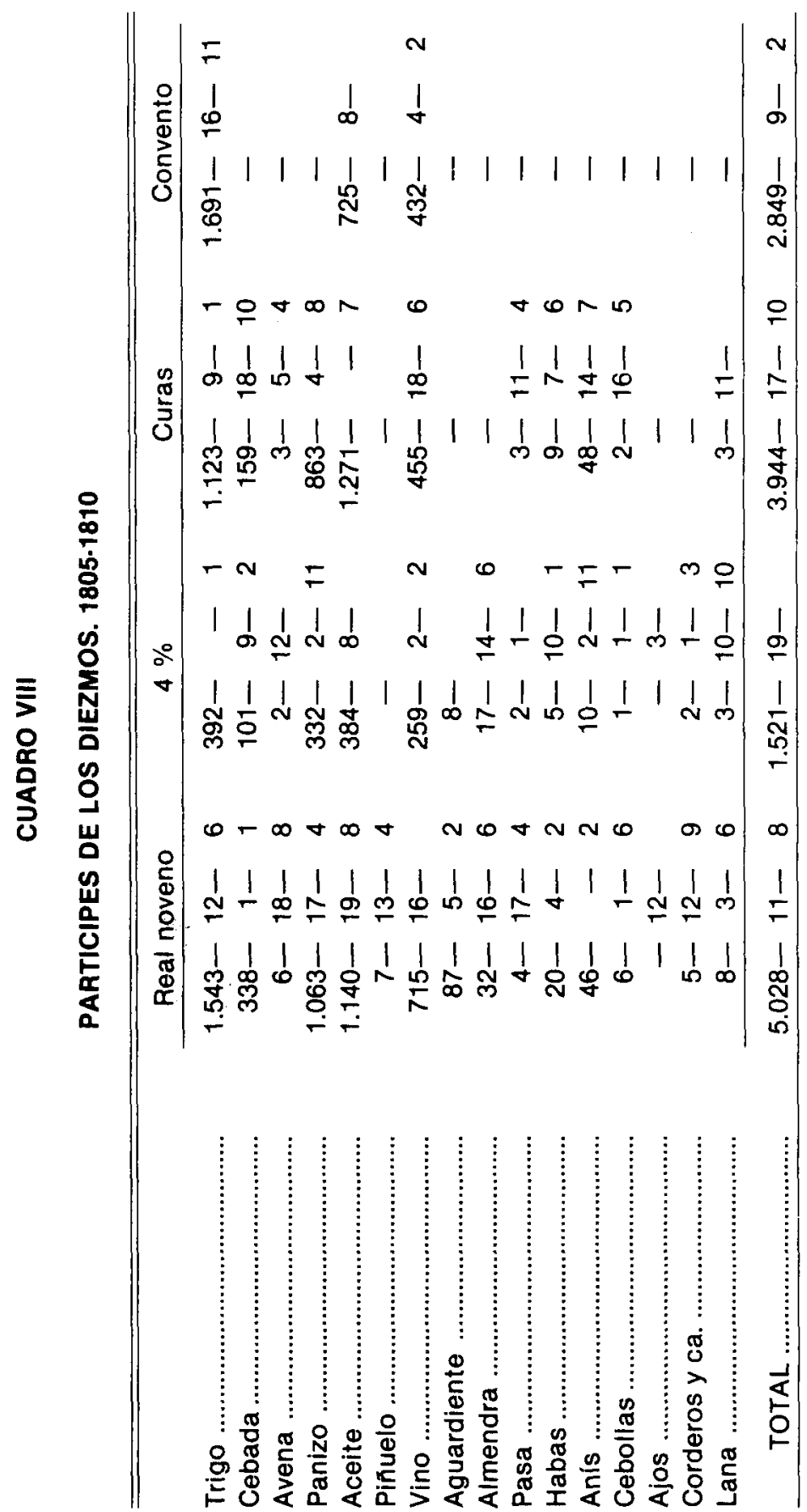




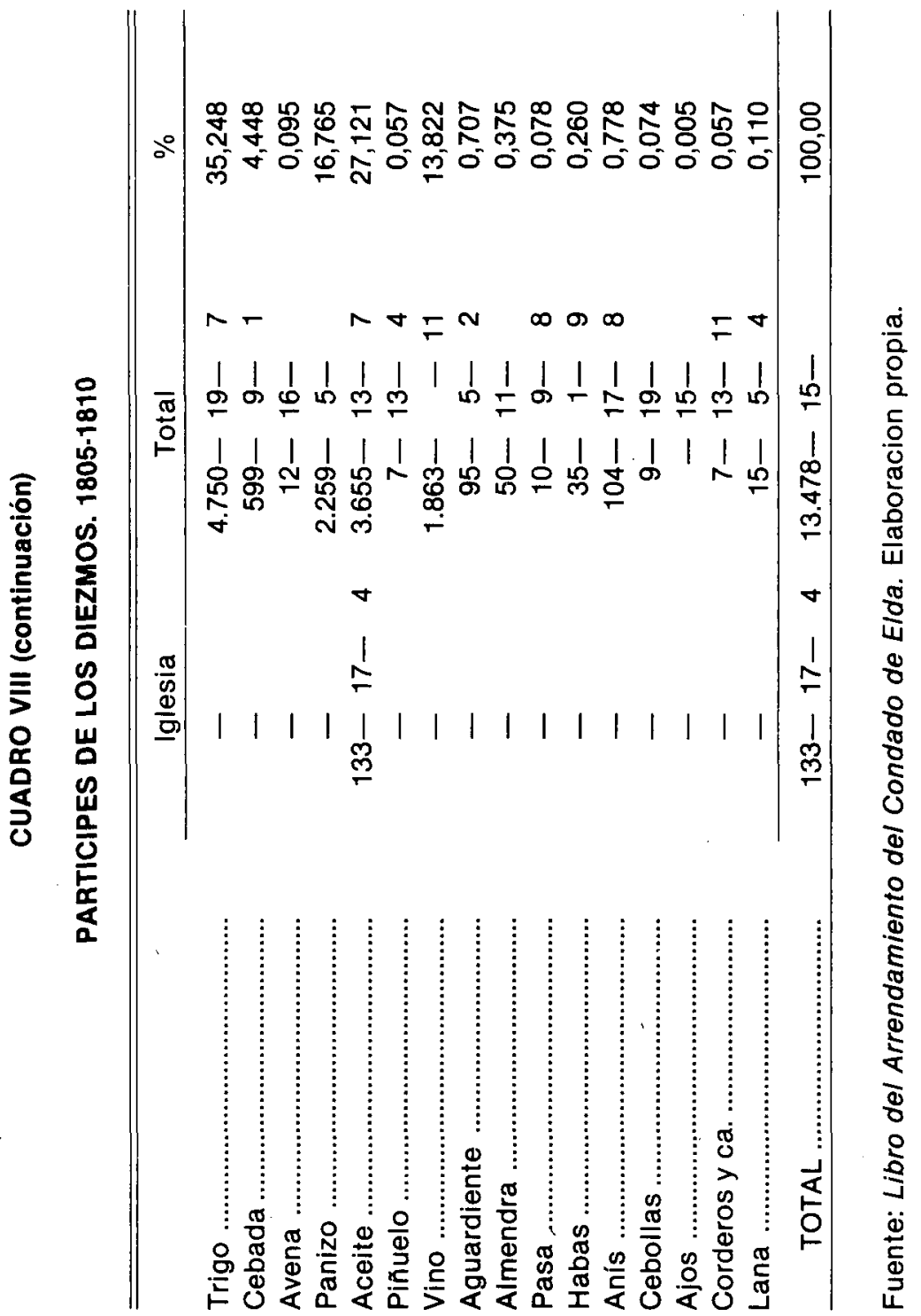


En los cuadros VII y VIII hemos recogido los datos relativos a los partícipes. En los cuadros que aparecen en el apéndice se detallan más pormenorizadamente los anteriores datos. A través de ellos se observa, en primer lugar, el distinto peso de cada uno de los productos, muy en relación con lo que se ha visto en los cuadros anteriores:

\begin{tabular}{|c|c|}
\hline & $\%$ total participes \\
\hline Trigo . . . . . . . . . . . . & 35,24 \\
\hline Aceite . . . . . . . . . . & 27,12 \\
\hline Panizo .............. & 16,76 \\
\hline Vino $\ldots \ldots \ldots \ldots \ldots \ldots$ & 13,82 \\
\hline \multirow[t]{2}{*}{ Cebada............... } & 4,44 \\
\hline & 94,36 \\
\hline
\end{tabular}

Esta cantidad es aportada solamente por cinco de los dieciséis productos que se recogen en los cuadros.

En segundo lugar, el total llevado por cada uno de los partícipes se ordena de la siguiente manera:

\begin{tabular}{|c|c|}
\hline & $\%$ total participes \\
\hline Real Noveno $\ldots \ldots \ldots \ldots$. & 37,3 \\
\hline Curas $\ldots \ldots \ldots \ldots \ldots$ & 29,3 \\
\hline Convento ............. & 21,1 \\
\hline Cuatro por ciento $\ldots \ldots \ldots$ & 11,3 \\
\hline \multirow[t]{2}{*}{ Iglesia $\ldots \ldots \ldots \ldots \ldots \ldots$} & 1,0 \\
\hline & 100,0 \\
\hline
\end{tabular}

Sobresale, por lo tanto, el Real Noveno, un impuesto muy reciente, que supuso una importante merma de las rentas de los arrendatarios (ver la nota 34), y que se aplicaba sobre todos los productos recibidos en especie; a todos afectaba también el Cuatro por Ciento, de casi todos percibian los curas de las tres parroquias su asignación, pero no sucedía lo mismo, como puede verse, con las percepciones del convento y de la Iglesia. Finalmente, hay que destacar la diferencia existente entre lo que supuso la participación de los años 1805 y 1806 del total y la de los años siguientes, entre los que sobresale, a su vez, el de 1810. La primera, debido a que no consta en esos años la participación de los curas, y la segunda, por la subida de los precios que se dio en ese último año. 
En consecuencia, el valor total de los diezmos de la villa de Elda era:

\begin{tabular}{|c|c|c|c|c|c|c|}
\hline \multirow{4}{*}{$\begin{array}{l}\text { VALOR NETO } \\
\text { DIEZM. DIN. } \\
\text { PARTICIPES. }\end{array}$} & $\uparrow 805$ & 1806 & 1807 & 1808 & 1809 & 1810 \\
\hline & $4835-3-5$ & $4498-7-7$ & $5616-13-10$ & $6773-11-6$ & $5699-1-4$ & $7701-\quad-2$ \\
\hline & $465-13-$ & - & - & - & $792-2-$ & $789-15-$ \\
\hline & $1051--8$ & $803-13-$ & $2710-5-3$ & $2659-15-5$ & $2474-14-7$ & $3779-6-1$ \\
\hline & $6351-17-1$ & $5302--7$ & $8326-19-1$ & $9433-7-11$ & $8965-17-11$ & $12270-1-3$ \\
\hline
\end{tabular}

De ahi que el total de los diezmos fuera durante los seis años abarcados 56.650-3-10 libras-sueldos-dineros, que suponen una media de 8.44113-11 (lib.-suel.-din.), cantidad aproximada debido a la falta de datos sobre los diezmos en dinero en los años 1806, 1807 y 1808.

\section{Las rentas de Petrel y de Salinas.}

\subsection{Las rentas de Petrel.}

Más arriba sólo hemos podido precisar la cantidad que pagaban los vecinos de esta villa por los pechos, a través del Libro Padrón de Haciendas; en cambio, la cantidad correspondiente a los diezmos "deducidos los partícipes", valorada "por la Junta de conformidad con los peritos", según la misma fuente, nos parece notablemente reducida, 4.495 reales, equivalentes a 300 libras, que sumadas a las 235 libras que, según la Concordia, debían pagarse a la Iglesia y a los curas de la Parroquia, se elevarían a 535 libras. Por otra parte, no constan, como sabemos, en el Libro del Arrendamiento del Condado, el Real Noveno ni el Cuatro por Ciento de la villa.

Según la última fuente, el colector de la villa de Petrel entregó a la administración del arrendamiento del Condado:

$$
\begin{array}{lll}
1805 & 2258-15-5 & \text { Libr.-Sueld.-Din. } \\
1806 & 4382-7-7 & \text { Libr.-Sueld.-Din. }
\end{array}
$$

De las cuales corresponderían a los diezmos y regalías, restadas las 800 libras de los pechos:

$\begin{array}{lll}1805 & 1458-15-5 & \text { Libr.-Sueld.-Din. } \\ 1806 & 3582-7-7 & \text { Libr.-Sueld.-Din. }\end{array}$

En cambio, según el Libro Padrón de Haciendas, los diezmos y las regalías habrian alcanzado solamente la cantidad de:

$$
\begin{aligned}
& \text { Diezmos ........535 Lib.-Suel. } \\
& \text { Regalias .......6.67-5- Lib.-Suel. } \\
& 602-5 \text { Lib.-Suel. }
\end{aligned}
$$


Cantidad muy reducida, aunque haya que añadirle el Real Noveno y el Cuatro por Ciento.

\subsection{Las rentas de Salinas.}

Aquí se nos presenta un problema semejante al anterior. Más arriba se ha tratado de lo exiguo de los pechos del Lugar y de algunas de las regalías. Según el Libro del Arrendamiento, el colector entregó:

$$
\begin{array}{lcr}
1805 & 768-17-3 & \text { Lib.-Suel.-Din. } \\
1806 & 594-10- & \text { Lib.-Suel.-Din.(35) }
\end{array}
$$

Otro medio de acercarnos a las rentas de Salinas es la información que aparece en el documento citado en la nota 20 . Según éste, los productos del lugar eran en 1747 "sacados del Contralibro que tiene el Señorío del

\begin{tabular}{|c|c|c|c|}
\hline & Producción & Diezmo (1/10, Concord.) & Valor (Lib.S-D)/36) \\
\hline Trigo & 700 Cahices & 70 Cahices & $1365-$ \\
\hline Cebada . & 600 Cahices & 60 cahices & $480-$ \\
\hline Centeno & 120 Cahices & 12 Cahices & $144-$ \\
\hline Avena. . & 18 Cahices & 1 Cahices 4 Barcellas & 8- \\
\hline Panizo & 110 Cahices & (1/8) 13 Cahices 9 Barcellas & $206-5-$ \\
\hline Anís.. & 300 Arrobas & 30 Arrobas & $90-$ \\
\hline Barrilla & 150 Quintales & 15 Quintales & $67-10$ \\
\hline \multirow[t]{2}{*}{ Aceite } & No consta & & $\ldots$ \\
\hline & & & $2360-15-$ \\
\hline
\end{tabular}
mesmo que es quien cobra todos los diezmos":

Cantidad que, aunque indicativa, queda muy por encima de la que se da en el Libro del Arrendatamiento. Según esto, el valor de los diezmos y las regalías del lugar de Salinas debia ser superior a las 2.500 libras.

4. Conclusión: La valoración de las rentas del Condado.

Según los datos anteriores, la totalidad de las rentas del Condado estaban formadas: 
1) Villa de Elda:

LIBRAS-SUEL.DIN.

Pechos de la Villa .............

$1724-15-8$

Regalías (Media 1805/06)

$3119-1-$

Diezmos .

$8441-13-11$

Luismos (Media 1805/06)

$14-9-2$

Huerto (Media 1805/06)

$152-15-2$

TOTAL

$13542-14-11$

2) Villa de Petrel:

Pechos de la Villa .............

LIBRAS

Diezmos y regalías (Med. 1805/O6) .

800

TOTAL ..........

2520

3320

3) Lugar de Salinas:

LIBRAS-SUEL.-DIN.

Pechos del Lugar . . . . . . . . . . .

Regalias (No mesón) (Med. 1805/06)

$35-2-1$

Diezmos (Estimación anterior) ....

$332-10-$

2360-15-

$2628-7-1$

Renta total del Condado

$19406-1-$

El arrendamiento del Condado ascendía a 15.000 libras, según la Escritura de 1784, en vigor durante los años aquí analizados (era la cuarta prórroga del arrendamiento), de las que hay que rebajar unas 2.246 libras, cantidad media anual que recibian los partícipes, según el cuadro VIII. Sin embargo, en el Libro del Arrendamiento del Condado, fol. 190, se halla la liquidación del Conde correspondiente a 1805: 
Pagos a cargo del Conde

(LIB.-SUEL.-DIN.)

Convento $609-2-8$

Iglesia y Fábrica $240-$

Cura de Elda

Vicario de Elda 200 -

Alcalde Mayor

$365-$

Alguacil Ordinario

$40-$

Maestra de Niñas

54-15-

Caridad Elda

$150-$

Hospital de Elda

$160-$

Almazaras del Condado

$2223-8-8$

Gastos (sic)

$853-17-1$

Cuatro por ciento

(37) $286-10-7$

Organista de Elda

$36-$

Sacristán y monaguillos

$80-$

Procurador.

$150-$

Pantano y aguas a Petrel

$28-10-$

Composición de diezmos y subsidio

Universidad de Valencia

$175-2-4$

Pechos

$1-18-9$

$5767-15-1$

TOTAL

$\frac{1-18-9}{5767-15-1}$

A esta cantidad hay que añadirle:

Iglesias de Petrel y Salinas

$495-$

Cargos munip. de Petrel y Salinas

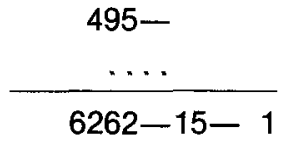

Cantidad que supone el $43,08 \%$ de la renta nominal a recibir por el Conde. A pesar de ello, el Condado de Elda produjo, en 1805, unas 9.000 libras liquidas al señor. 
(1) GIL OLCINA, A.: La Propiedad Señorial en Tierras Valencianas. Valencia, 1979.

CISCAR PALLARES, E.: Tierra y Señorio en el Pais Valenciano (1570-1620). Valencia, 1977.

(2) Carta de Población del Señorío de Elda. 1611-1612. Transcripción e introducción de G. Sánchez Recio. Elda (Alicante); 1979. En los capitulos 15 y 20 se tratan conjuntamente los mismos temas para Elda y Petrel. Sin embargo, existe una Concordia entre el Conde de Puñoenrostro y el Ayuntamiento del Lugar de Salinas, de 27 de noviembre de 1760, sobre las relaciones entre ambos. Ver el Apéndice, documento I.

(3) Agradezco desde aquí a don Francisco Corbf Berenguer, de Monóvar (Alicante), el haberme permitido utilizar esta fuente. Anteriormente fue consultada por A. Gil Olcina, de manera general, en la obra citada, págs. 96-97.

(4) Museo de Artes y Oficios de Monóvar. Agradezco aqui también la generosidad de don José María Román Amat.

(5) GIL OLCINA, A.: O. c., págs. 248-253.

(6) A(rchivo) (de) P(rotocolos) (de) M(onóvar): LEON VIDAL, P. (Escribano Público de la Villa de Elda): Protocolos, años 1757-1758. Año 1757, fols. 2-6. Del mismo modo agradezco las facilidades que se me han prestado para la consulta de estas fuentes notariales a don Miguel Velasco Pérez, Notario, y a don Jorge Luz Martínez, Oficial de la Notaría de Monóvar.

(7) No he podido hallar esta escritura, realizada ante el Notario de Valencia Miguel Ortis y Giner, el 12 de agosto de 1784.

A. P. M.: MIRA, C. (Escribano Público de la Villa de Monóvar): Protocolos de los años 17841785. 1784, fols. 151 v.-155. La fecha del arrendamiento y el precio del mismo constan también en el Libro del Arrendamiento del Condado, fol. 1.

(8) A. P. M.: MIRA, C.: Protocolo Citado, Fol. 152.

(9) A(rchivo) M(unicipal) (de) E(lda): Libro Capatrón de Haciendas de la Villa de Elda. 1777. Se mantuvo en vigor hasta 1820.

(10) A(rchivo) M(unicipal) (de) P(etrel): Libro Padrón de Haciendas de la Villa de Petrel. Año 1819. 2 volúmenes. Vol. Il, pág. 365.

(11) A(rchivo) M(unicipal) (de) S(alinas): Amillaramiento. Año 1818. Fol. 44. Aquí no se constatan las rentas dominicales y decimales. La relación entre el valor de la propiedad y de la renta es del $4 \%$. La equivalencia utilizada es de 15 reales por una libra.

(12) RUIZ TORRES, P.: Señores y propietarios. Cambio social en el sur del País Valenciano: 1650-1850. Valencia, 1981, págs. 90-91. El autor expone un modelo de clasificación de las rentas señoriales semejante al aqui utilizado. En nuestro trabajo faltan las rentas por /a jurisdicción porque ésta estaba reservada y, por lo tanto, no se arrendaban sus rentas.

(13) Carta de Población del Señorío de Elda, cap. VIII. Ver también el Asentamiento de Antoni Amat, adjunto a la Carta de Población, págs. 23-25.

(14) A. P. M.: FERRANDIS CARRATALA, J. (Escribano Público): Escrituras Públicas de Elda... Años 1752-61. Entre las Escrituras de 1754 hay varias concesiones de este tipo, fols. 4 y $6 \mathrm{v}$ 11.

- MONLLOR, A. (Escribano): Escrituras Públicas de Elda... Año 1763, fol. 82.

(15) SANCHEZ RECIO, G.: La estructura agraria y la tenencia de la tierra en el Señorio de Elda. Anales de la Universidad de Alicante. Historia Contemporánea. N. ${ }^{\circ}$ 1. 1982.

- La estructura agraria de Elda a finales del Antiguo Régimen. Anales de Historia Contemporánea. N.ำ 2 Murcia, 1982.

(16) Libro del Arrendamiento del Condado de Elda. Fol. 133 v.

(17) Libro Cobratorio de Pechos y Diezmos. Elda, 1809. Fols. 1-111. (Museo de Artes y Oficios de Monóvar).

(18) Censo de Floridablanca. Corregimiento de Orihuela. Academia de la Historia. 9/6252.

CASTELLO TRAVER, J. E.: El País Valenciano en el Censo de Floridablanca (1787). Valencia, 1978. Pág. 168. 
(19) CAVANILLES, A. J.: Observaciones sobre la Historia Natural, Geografía, Agricultura, Población y Frutos del Reino de Valencia. Dos volúmenes. Madrid, 1795-97. Il vol. Pág. 257 (Zaragoza, 1958).

(20) A. M. P.: Libro Padrón de Haciendas, loc. cit.

(21) A. M. P.: Se conservan aquí varios Libros de Giradora de los siglos XVII al XIX, aún no estudiados, en los que se halla la información más fiable sobre los pechos de la villa.

(22) Censo de Floridablanca. Corregimiento de Xixona, Sig. cit.

CASTELLO TRAVER, J. E.: O. cit. Págs. 455-456.

CAVANILLES, A. J.: O. cit. Pág. 260.

En un informe elaborado por el Ayuntamiento de Salinas, en 1747, se dice que la población consta de 80 vecinos: 29 vecinos contribuyentes de S. Mag., 28 jornaleros, 12 viudas pobres, 10 pobres de solemnidad y un exento.

A. M. S.: Legajo $1 .^{\circ}$ Actas Municipales 1741-1798. S/Fol.

(23) A. M. E.: Libro Giradora y Capatrón de la Villa de Elda. Año 1716. Nota de los pechos que corresponden los becinos y terratenientes del lugar de Salinas a la Señoria del Conde, mi Señor, de Elda, en algunas casas y huertas de dicho lugar. En el documento citado (nota 22) se dice que «la huerta... corresponde anualmente al Señorio veinte y tres libras y sueldos moneda corriente".

(24) RUIZ TORRES, P.: O. cit., págs. 77 ss.

(25) MOXO, S. de: La disolución del Régimen Señorial en España. Madrid, 1965. Págs. 52. 54.

- GIL OLCINA, A.: O. C., págs. 52-53.

(26) A. P. M.: LEON VIDAL, P. (Escribano de la Villa de Elda): Protocolos de... Años 17591761. Año 1760, fols. 69-72: Concordia del Excmo. Sr. Conde de Puñoenrostro, mi Señor, con el Ayuntamiento del Lugar de Salinas.

El origen del conflicto y del pleito había estado en la falta de respeto a las regalías señoriales del mesón, la tienda, y otras por varios vecinos de Salinas. A. M. S.: Legajo 1. ${ }^{\circ}$ : Actas de 1759,16 de noviembre.

(27) GIL OLCINA, A.: O. cit., págs. 55-56.

(28) MESTRE SANCHIS, A.: La recolección de diezmos en la diócesis valenciana según la encuesta capitular de 1758. Acta del I Congreso de Historia del Pa/s Valenciano, 1976, vol. III, págs. 631-642.

(29) A. H. N.: Legajo 4.181. Sección de Consejos.

(30) A. M. E.:Precess de 1630. "Concordia entre el Cardenal de Cartagena y el Conde de Cocentaina sobre los diezmos de las Villas de Elda, Aspe, Petrel y Lugar de Salinas, 1494".

(31) Carta de Población del Señorio de Elda, págs. 5, 15, 16, 20.

(32) En la Concordia firmada por el Conde de Elda con la población de la villa, en 24 de enero de 1684, se establecia la desaparición de los pechos viejos, por lo que esas tierras se convertian en alodiales, de natural, pero se insistia en la obligación de pagar el diezmo. A. M. E.: VARIOS (carpeta): Papeles interesantes al pueblo de Elda. 1771-72.

(33) A. M. E.: VARIOS (carpeta): Papeles interesantes... 1771-73. «Real Cédula de Su Majestad, en que se sirve aprobar la Concordia otorgada entre el Illmo. y Rvdmo. Señor Don Joseph Tormo, Obispo de Orihuela, y el Excmo. Señor Don Francisco Javier Arias, Centurión etc., Conde de Puñoenrostro, Anna, etc., en la Villa y Corte de Madrid, a 27 de octubre de 1769. Para que nada falte de lo necesario al Culto Divino y pasto espiritual de las parroquiales Iglesias de Elda, Petrel y Salinas de dicha Diócesis, según en ella se expresa».

(34) El cuatro por ciento es la parte de los diezmos que recibia el Obispo de Orihuela. En la documentación utilizada no se hace referencia a la resolución del pleito al que se alude en la Escritura de arrendamiento de 1757 sobre el cuatro por ciento destinado al Seminario de Orihuela. 
El Real Noveno se comenzo a pagar en 1801, fue autorizado por un Breve Pontificio del 3 de octubre de 1800 e impuesto por un Real Decreto del 26 de enero de 1801. En el Reglamento para el cobro se establecía que cel noveno se extraía antes que ninguna otra detracción y sin excepción en favor de ninguna clase de perceptores...n. ARTOLA, M.: La Hacienda del Antiguo Régimen. Madrid, 1982. Págs. 358-359.

En el Libro del Arrendamiento el Real Noveno se deduce antes que ninguna otra participación, no contando su importe entre lo administrado por los arrendatarios; en cambio, el cuatro por ciento y las demás participaciones eran administradas por ellos.

(35) Dicha cantidad se especifica del siguiente modo: Libras-Sueldos
$59-10$
Diezmo de la lana valenciana
80
Diezmo (sic)
147
Diezmo de la cebada
166
Diezmo del aceite
142
Sin especificar

Estas cantidades las consideramos incompletas, ya que sólo las regalias conocidas de Salinas superan con mucho esas 142 libras no especificadas.

(36) Los precios son las medias de los que figuran en el CUADRO V, que aproximadamente son tres veces más altos que los de 1747; de ahí que hayamos multiplicado por tres los precios de los productos que no constan en dicho cuadro.

(37) Cantidad superior a la extraida del Libro del Arrendamiento para ese año. 


\section{APENDICE DOCUMENTAL}

I. CONCORDIA DEL EXCMO. SR. CONDE DE PUÑOENROSTRO, MI SEÑOR, CON EL AYUNTAMIENTO DEL LUGAR DE SALINAS

En el Lugar de Salinas, a los ventisiete días del mes de Noviembre de mil setecientos y sesenta años. Ante mi el Escribano y testigos infraescritos parecieron de parte una el Excelentísimo Sr. Conde de Puñoenrostro, Elda y Anna, etc. mi Señor, y en su nombre Don Andrés Maximino Calvo, su secretario, Contador y Apoderado General, según la Escritura autorizada en la Villa y Corte de Madrid, en el día trece de Agosto pasado de próximo de este año, por el Escribano Domingo Joseph de Cares, que de ser bastantes los poderes para el Ingraescrito yo el Escribano doy fe.

Y de parte otra Juan Ignacio Juan, Alcalde Ordinario, Pedro Asorín y Pedro Maestre, Regidores, y Juan de Antonio, Síndico y Procurador General, Consejo, Justicia y Regimiento de dicho Lugar, y dijeron: Que hallándose dicho Sr. Excmo. en la quieta y pacífica posesión de Inmemorial del Dominio, Señorío y Vasallaje, Jurisdicción Civil y Criminal, Mero y Mixto Imperio de dicho Lugar y su término, con la percepción de los Diezmos de todo género de frutos y hortalizas, que son de cada diez una, a excepción del panís, que es de cada ocho uno; de las primicias, terrajes y pechos, con el goce igualmente de varios derechos y regalías, como son: de tener tienda, panadería y taberna, casa mesón, horno de vidrio, derecho de borra, con el uso de las yervas del término de este dicho Lugar en nueve meses de los doce del año y el derecho de arrendarlas a cualquier ganadero, y de persivir el cabesaje, que son cuatro dineros por cabeza de ganado cabrio (fol. 1 v.) todo en fuerza de legítimos títulos, como dueño y Señor del Condado de Elda en que el está comprendido dicho Lugar:

Se han sucedido por parte de este algunos pleitos con el motivo de pretender algunos de sus vecinos poder admitir en sus casas pasajeros, tener el arbitrio y grangeria de aprovecharse del estiercol y de otras utilidades en perjuicio de la referida casa mesón y contra Resolución de los Señores de la Real Audiencia de Valencia de diez y siete días del mes de marzo de mil setecientos cincuenta y cinco, expedida ante el Secretario de Cámara Joaquín Lombart, como igualmente por tener otra tienda abierta dicho Común en perjuicio de la dicho Sr. Excmo., sobre lo que está pendiente pleito en la misma Real Audiencia, temiéndose no menos otros por resistirse algunos de los vecinos al pago del mencionado derecho de cabezaje, y sobre aprovecharse de las yervas, todo to que ha motivado la menos buena correspondencia que debe haber entre dicho Lugar, sus vecinos y dicho Sr. Excmo. su Dueño, e deseando evitar discordias, pleitos y gastos entre ellos y todo perjuicio de parte a parte, se ha tratado, madurado de los medios más proporcionados para el logro de tan justos deseos, conviniéndo- 
se amigablemente ambas partes en lo que en esta Escritura se expresará, y para su efecto, siendo ciertos y sabedores de su derecho, el que les pertenece en este caso, de su firme voluntad y como mejor haya lugar de derecho, se avienen y concuerdan los capítulos, pactos y condiciones siguientes:

1. ${ }^{\circ}$ Primeramente es pacto y condición que Su Excia. haya de continuar en la misma quieta y pacífica posesión en que está del Dominio, Señorio, Vasallaje, Jurisdicción, Civil y Criminal, Mero y Mixto Imperio, de dicho Lugar y su término, como dueño y Señor del Condado de Elda, en el que se halla este comprendido, y de la percepción de los Diezmos de todos los frutos y hortalizas, de cada diez uno, a excepción del panizo que se paga de cada ocho uno, según y en la conformidad que hasta ahora se ha acostumbrado, sin ponérsele el menor impedimento ni embarazo.

2. Otrosi: Es pacto y condición que igualmente haya de continuar dicho Sr. Excmo. en la misma quieta y pacífica posesión de percibir (fol. 2) los derechos de terrajes y los pechos, según y en la conformidad que hasta el presente les ha percibido y se le han pagado sin ponérsele el menor impedimento ni embarazo.

3. ${ }^{\circ}$ Otrosi: Es pacto y condición que por cuanto hay pleito pendiente entre el Reverendo Cura Párroco de dicho Lugar y Su Excia. sobre la pertinencia de dichas primicias en la Curia Eclesiástica de este Obispado de Orihuela, en el caso de obtener Su Excia. sentencia favorable en dicho pleito haya de continuar en la misma quieta y pacífica posesión que ha estado dicho Sr. Excmo. de percibir dichas primicias de todos los frutos y hortalizas, según y en la conformidad que se han acostumbrado de pagar.

4. Otrosi: Es pacto y condición que también haya de continuar dicho Excmo. Sr. en la propia quieta y pacífica posesión de tener horno de vidrio privativa y prohibitivamente, como asimismo casa mesón, sin facultad alguna a ningún vecino de dicho Lugar de poder admitir en sus casas pasajeros, haciendo arbitrio y grangería, recibiendo por el hospedaje alguna utilidad.

5. Otrosi: Es pacto y condición que dicho Sr. Excmo. alarga y traspasa a favor del Común de dicho Lugar las referidas tienda, panadería, y taberna, por cuyo goce ha de pagar a Su Excia. sesenta y cinco libras, moneda corriente de este Reino, en cada un año y en los plazos que abajo se expresarán.

6. Otrosi: Es pacto y condición que asi mismo se de alarga y traspasa dicho Sr. Excmo. a favor de dicho Común el derecho de cabezaje, por cuyo goce se han de pagar a Su Excia. por el mismo Común cinco libras de dicha moneda en cada un año en los plazos que abajo se dirán. 
7. Otrosi: Es pacto y condición que dicho Sr. Excmo. se de alarga y (fol. 2 v) traspasa a favor del Común de dicho Lugar el aprovechamiento de las yerbas de su término en los referidos nueve meses, con la condición expresa y no sin ella de poder tener Su Excia. en el mismo un rebaño de ganado lanar de doscientas cabezas en los tiempos que quiera Su Excia. (a excepción de la Redonda) y de conceder para ello su licencia y permiso a la persona que bien vista le fuera, sin que se le ponga embarazo ni impedimento alguno, haciendo observación a la Justicia de dicha licencia por escrito, obligándose por este capítulo como se obliga dicho Común a pagar anualmente a Su Excia. veinte libras en los mismos plazos que abajo se expresarán, y sin perjuicio alguno del derecho privativo de Su Excia. en establecer los realengos según hasta ahora lo ha practicado de inmemorial.

8. ${ }^{\circ}$ Otrosi: Es pacto y condición que las noventa libras que importan los tres derechos y regalías que se de Su Excia. a favor del Común en los capítulos quinto, sexto y séptimo las haya de pagar al Apoderado de su Excia., su Arrendador o Colector de sus derechos dominicales. El Arrendador de la tienda en tres plazos, esto es, el primero por todo el mes de abril, el segundo por todo agosto, y el tercero y el último por todo el mes de diciembre, por cuyas pagas y por cada una de ellas ha de poder despacharse Execución por parte de Su Excia. contra dicho Arrendador quedando así mismo obligado dicho Común al pago de las cantidades que no pudiesen cobrarse del Arrendador de dicha tienda y sus fiadores por no haber tomado las correspondientes seguridades al tiempo de hacerse la Escritura de arriendo.

9. Otrosi: Es pacto y condición que para la mayor seguridad de Su Excia. en el cobro de dichas noventa libras quede como queda por este capítulo hipotecada especialmente la referida regalía de panadería, tienda y taberna.

10. Otrosi: Es pacto y condición que por cuanto quedan cedidos por Su Excia. a favor de dicho Común las referidas regalías de tienda, panadería y taberna, derecho de cabezaje y aprovechamiento de las yerbas (fol. 3) en los mencionados nueve meses puede libremente arrendarlas a la persona que bien vista le fuere sin intervención de Su Excia. quedando responsable dicho Común al pago de las referidas noventa libras, según y en la conformidad que queda estipulado en los capítulos antecedentes.

11. ${ }^{\circ}$ Otrosi: Es pacto y condición que cuanto queda estipulado en esta Escritura se ha de entender y entiende sin perjuicio alguno de los títulos que tiene Su Excia. de la pertinencia del Dominio, Señorío y Vasallaje de este Lugar y su término, ni cualesquier otro derecho y regalía que en fuerza de dichos títulos tuviere Su Excia., los que deben quedar y quedan en su fuerza y vigor. 
12. Otrosi: Es pacto y condición que el salario de esta Escritura y sus copias se han de pagar por ambas partes y mitad.

13. ${ }^{\circ}$ Otrosi: Es pacto y condición que en caso de contravención a cualesquier de los capítulos estipulados en esta Escritura, sin perjuicio.alguno de esta, y quedando siempre en su misma fuerza y vigor, la parte que contraviniere haya de pagar en pena a la otra parte cincuenta libras a más de satisfacer todos los daños y perjuicios que se ocasionaren por dicha contravención.

14. Otrosi: Es pacto y condición que para la mayor firmeza y validación de esta Escritura se haya de solventar por ambas partes contrayentes su aprobación del Real y Supremo Consejo de Castilla, subministrándose antes por la de dicho Común la información de utilidad para su obtento.

Y en la forma referida bajo de las condiciones y capitulos de convención y ajuste que van expresados, se hace, otorga y celebra esta Concordia y transacción, por la cual quedan rotas y canceladas y por tales las dan y tienen los otorgantes todas las instancias judiciales y extrajudiciales que tengan (fol. 3 v.) pendientes y quieran introducir...

...Y todo lo estipulado en esta Escritura lo han, aceptan, aprueban, ratifican y confirman desde la primera línea hasta la última, respectivamente del modo, manera y forma predicha, según su más genuina y literal inteligencia...

APM: Protocolos de Pedro León Vidal. Escribano de la Villa de Elda. 17591761. Año 1760 , fols. $69-72$. 
II. CONCORDIA ENTRE EL CARDENAL DE CARTAGENA Y EL CONDE DE COCENTAINA SOBRE LOS DIEZMOS DE LAS VILLAS DE ELDA, ASPE, PETRER Y LUGAR DE SALINAS, 1494.

Lo que por parte del Espectable Señor Conde de Cosentayna se ofresce e apunta al Reverendissimo Señor Cardenal de Cartagena sobre la diferencia que el dicho Espectable Señor Conde tiene con su Señoria Reverendissima y su Iglesia de Cartagena acerca de los diezmos de los Lugares de la Villa de Elda que son del dicho Espectable Conde los quales son en la Diocesis de Cartagena conviene a saber Elda, Aspe, Petrer, y Salinas es lo siguiente.

Primeramente porque en el pagar los diezmos de los dichos Lugares por ser como son poblados de Moros se esperan aver grandes inconvenientes el dicho Espectable Conde de e pague en cada un año perpetuamente para siempre jamás a los Señores Obispo Dean y Cabildo de la dicha Iglesia de Cartagena Doscientas Libras de moneda Reales de Valencia por la parte que a ellos cabe de los diezmos de los dichos Lugares pagados a Todos los Santos y a Navidad de cada un año puestos en la Ciudad de Murcia, y que luego comiense a pagar este presente año de noventa y quatro, $y$ cerca de ello se otorguen las Capitulaciones en cientos necesarios como sea seguro para la dicha Iglesia y en entre las otras que si dos años el dicho Espectable Conde o los que despues del ternan los dichos Lugares estuvieren que no paguen las dichas doscientas libras que desde entonces queden libres a la dicha Iglesia e Señores Obispo Dean y Cabildo de ella todos los diezmos de los dichos Lugares assi lo que les pertenecen como los de dicho Espectable Conde.

Ittem que el dicho Espectable Conde allende de pagar las dichas doscientas libras sea obligado a tener un Clérigo y un Rector en la Villa de Aspe, e otro en Elda para que sirvan y administren los Sacramentos a los Christianos vezinos de las dichas Villas e pagar a las fábricas de las dichas Iglesias lo que será justo para ornamentos y sus necesidades.

Ittem que de todo el susodicho se aya confirmación de nuestro Señor el Papa e se espidará dos bulas una para la Iglesia y otra para el Señor Conde y lo que costaren expedir lo pague el dicho Espectable Conde.

Ittem que de todo lo devido por el dicho Espectable y por sus Antepasados de los diezmos de los dichos Lugares a la dicha Yglesia de Cartagena el dicho Señor Cardenal y su Cabildo le fagan gracia e quita con tanto queden al dicho Cabildo ciento y cinquenta libras valencianas luego y satisfaga y contente al Canonigo Pero Rois de Montalegre de los frutos de los años de noventa noventa y uno, e noventa y dos de la parte del Obispo que ha de aver como arrendador que fue de los dichos frutos en los dichos años e que de e pague a los dichos Señores Cardenal y su Cabildo por los 
frutos del año noventa y tres passado doscientas libras reales sueldos de Valencia.

E si por casso el dicho Señor Reverendissimo Cardenal no quisiese aceptar el partido de la dicha compusición de las dichas doscientas libras que el dicho Espectable Conde dexe libre e desembargadamente los diezmos de los dichos lugares a la dicha Iglesia de Cartagena, e desde agora de para ello siguridad e quede asentado que an de pagar los vezinos de los dichos Lugares los diezmos de la pansa, trigo, cevada, centeno, de alcandia, e migo e de todos los otros frutos e panes, e açafranes, e aceyte e de todas las otras cosas e simientes que Dios les diere, e de los ganados que tuvieren las crianças de los corderos e cabritos, lana y queso e de todas las otras cosas en la manera e segun se pagan en los Lugares de Montforte, Elche, Albatera y los otros del dicho Obispado de Cartagena de la parte de Aragón e de los dichos diezmos el dicho Espectable Conde desmando a la ochena como hoy se hase en los dichos Lugares lleve el quinto primero y después de lo que quedare el tercio e que de ello pague al Rector y fabricas y la dicha Yglesia de Cartagena lleve dos partes, y si desmaren diezmos se parta en tres tercios, el dicho Espectable Conde lleve una y la Iglesia las dos lo qual todo se entienda solamente en los Lugares de Elda, Aspe y Petrel y no Salinas porque aquel es comarca del dicho Reverendissimo Cardenal en su Cabildo e los diezmos solamente son de aquellos e en casso que el dicho Espectable Conde huviere de dexar los dichos diezmos que por la necesidad que tiene del arrendamiento que tiene fecho de sus lugares que los dichos Señores Cardenal y su Iglesia se los arrienden por quatro años por precio en cada un año de ciento y cinquenta libras reales de Valencia cumpliendo todas las cosas susodichas.

En la Vilia de Aspe de la Diocesis de Cartagena sabado a treynta del mes de Agosto año del Nacimiento de nuestro Salvador Jesuchristo de mil e quatrocientos noventa e quatro años el muy Spectable Señor Don Juan Corella Conde de Cosentayna e Diego Rodrigues de Sant Esidro Canonigo en las Iglesias de Salamanca e Cartagena Provissor Oficial y Vicario General en todo el Obispado de Cartagena por el Reverendissimo in Christo Padre el Señor Don Berlandino Lopez de Caravaxal por la miseración Divina del Titulo de Sant Marselino e Sant Pedro Cardenal de la Santa Iglesia Romana y por virtud que de su Señoria Reverendissima tiene, y el dicho Provisor y los Señores Gil Sanchez Canonigo e Lorenzo Gil Racionero de la Iglesia de Cartagena todos tres por virtud del poder que tienen de los Señores Dean y Cabildo de la Iglesia de Cartagena segun que ante mi el Notario Infraescrito esta e paso otorgaron y se obligaron de cumplir la susodicha capitulacion excepto que quanto que dexe que en caso que el Reverendissimo Cardenal de Cartagena no acepte el partido de la compusicion de las doscientas libras que el Señor Conde y sus Vasallos ayan de dexar los diezmos libremente a la Iglesia de Cartagena como en la dicha Capitula- 
ción se contiene e los ayan de pagar de la manera en ella declarada que aquesto no sea el dicho Conde ni sus vasallos obligado a hazer sino solamente pagar del modo e manera que se pagaren de Novelda y Monovar y los otros del Señor Don Pedro Maça de Liçana que tiene en su Obispado de Cartagena.

(Archivo Municipal de Elda: Process de 1630) 


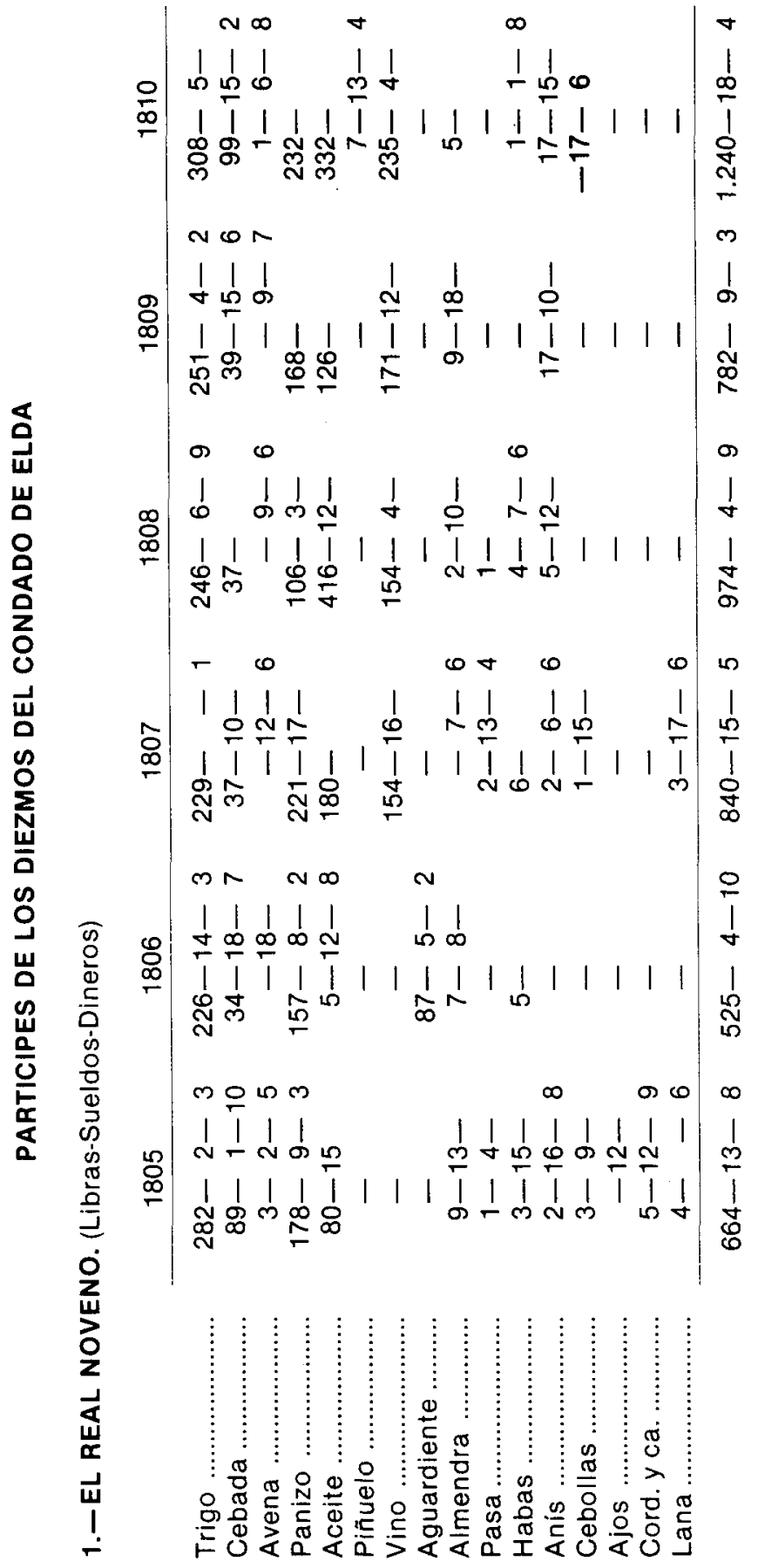




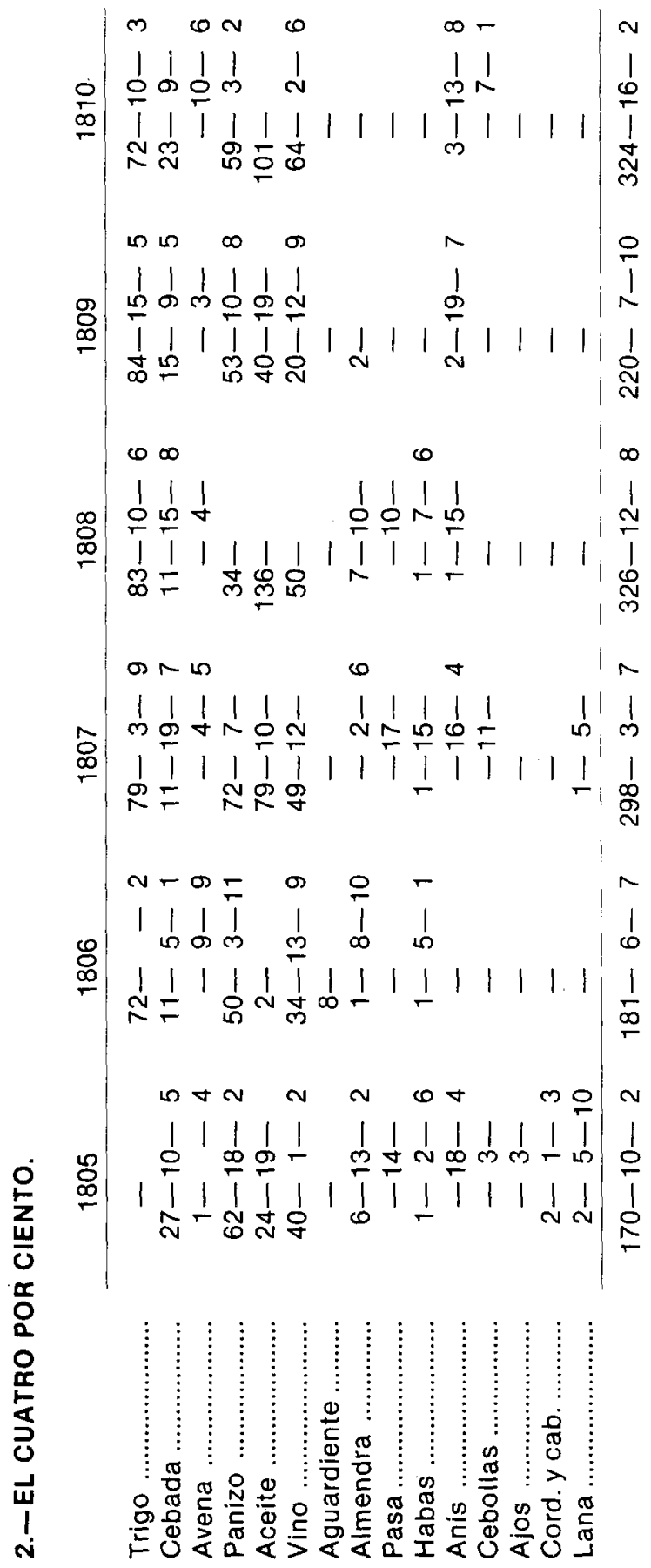




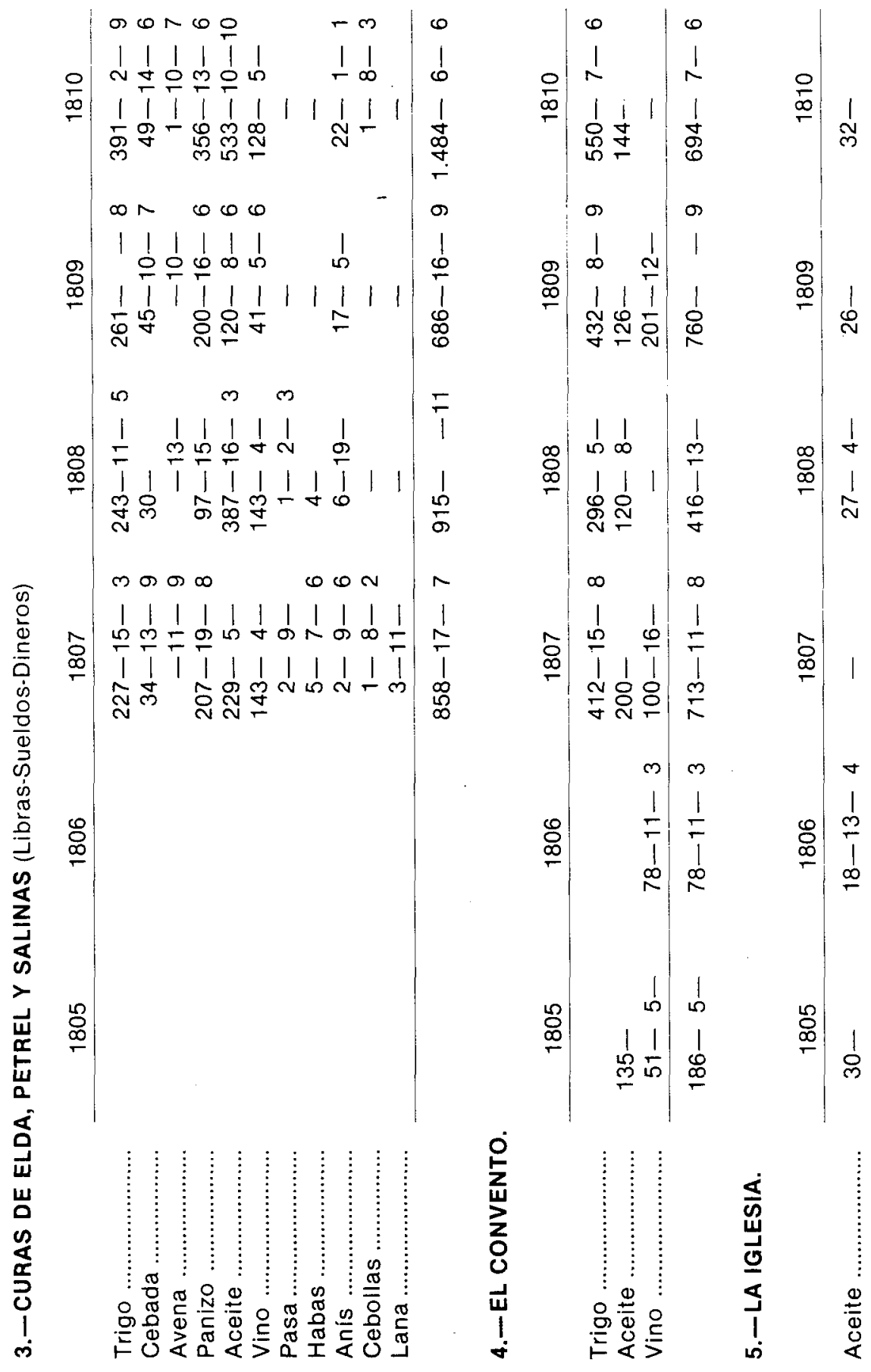

